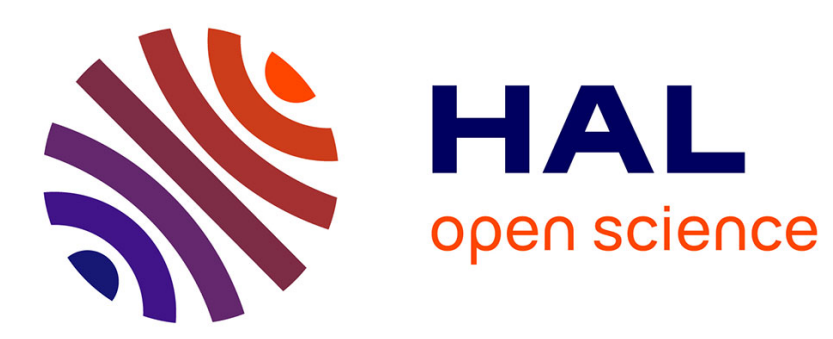

\title{
Host-Guest Chemistry of Dendrimers in the Gas Phase
} Zhenhui Qi, Christoph A. Schalley

\section{To cite this version:}

Zhenhui Qi, Christoph A. Schalley. Host-Guest Chemistry of Dendrimers in the Gas Phase. Supramolecular Chemistry, 2010, pp.1. 10.1080/10610278.2010.486438 . hal-00599222

\section{HAL Id: hal-00599222 https://hal.science/hal-00599222}

Submitted on 9 Jun 2011

HAL is a multi-disciplinary open access archive for the deposit and dissemination of scientific research documents, whether they are published or not. The documents may come from teaching and research institutions in France or abroad, or from public or private research centers.
L'archive ouverte pluridisciplinaire $\mathbf{H A L}$, est destinée au dépôt et à la diffusion de documents scientifiques de niveau recherche, publiés ou non, émanant des établissements d'enseignement et de recherche français ou étrangers, des laboratoires publics ou privés. 


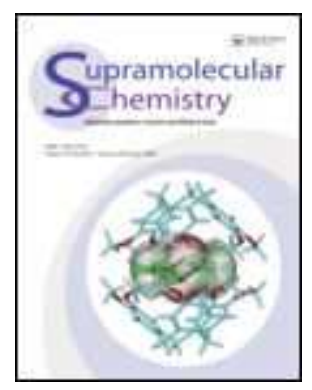

\section{Host-Guest Chemistry of Dendrimers in the Gas Phase}

\begin{tabular}{|r|l|}
\hline Journal: & Supramolecular Chemistry \\
\hline Manuscript ID: & GSCH-2010-0032.R1 \\
\hline Manuscript Type: & Special Issue Paper \\
\hline Date Submitted by the \\
Author: & $13-$ Apr-2010 \\
\hline Complete List of Authors: & $\begin{array}{l}\text { Qi, Zhenhui; Freie Universität Berlin, Institut für Chemie und } \\
\text { Biochemie } \\
\text { Schalley, Christoph; Freie Universität Berlin }\end{array}$ \\
\hline Keywords: & $\begin{array}{l}\text { host-guest chemistry, dendrimers, gas-phase chemistry, mass } \\
\text { spectrometry, supramolecular chemistry }\end{array}$ \\
\hline
\end{tabular}

\section{\scholaroNE" \\ Manuscript Central}




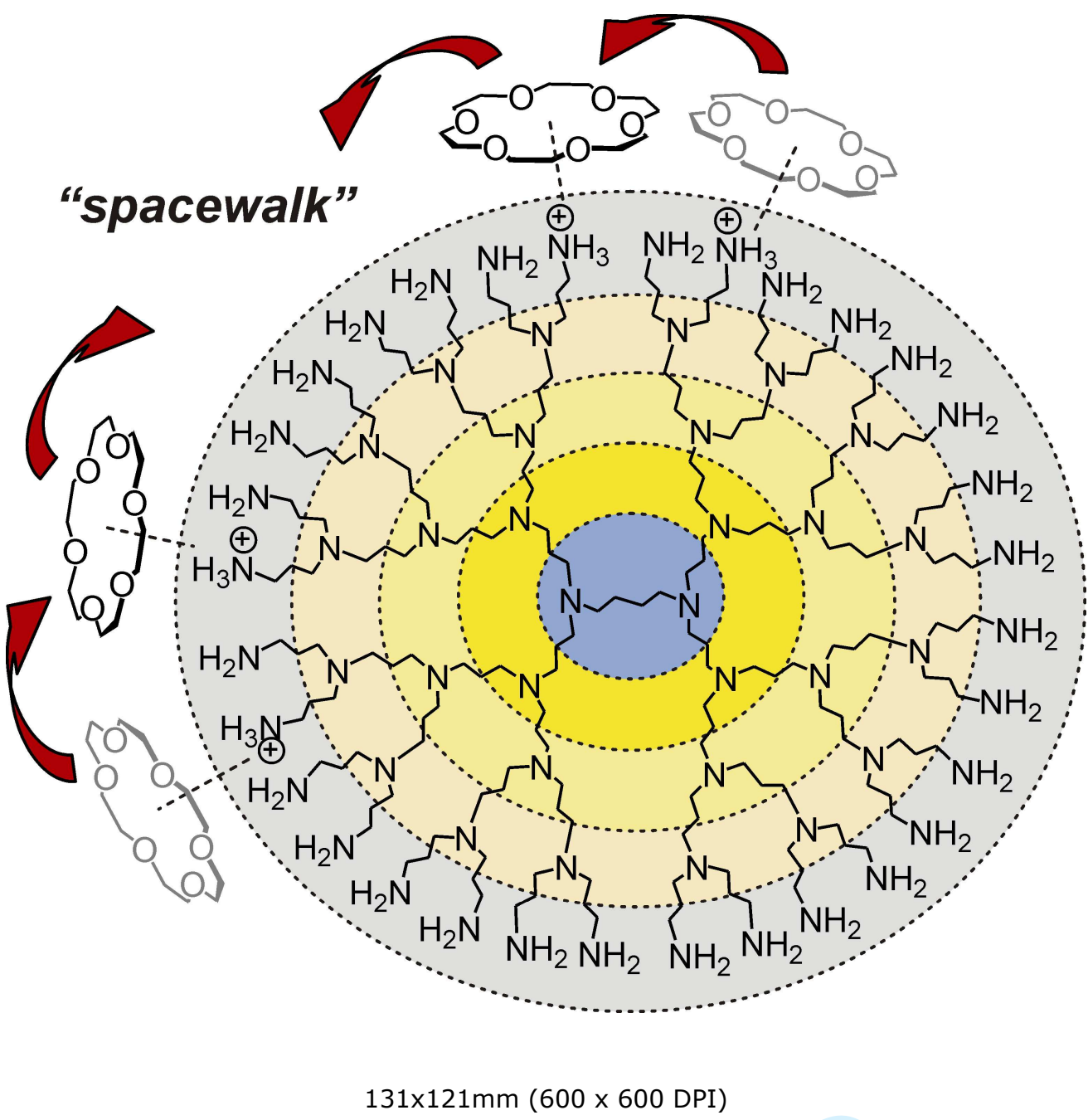




\title{
Host-guest chemistry of dendrimers in the gas phase
}

\author{
Zhenhui Qi and Christoph A. Schalley* \\ Institut für Chemie und Biochemie, Freie Universität Berlin, Takustraße 3, 14195 \\ Berlin, Germany \\ Dedicated to the memory of Dmitry Rudkevich, who died much too early. Those who \\ have worked with him certainly know his very supportive optimism when showing \\ complicated NMR spectra to him: "Don't worry, I can see, it's in there!"
}

Corresponding author. E-mail: christoph@schalley-lab.de

\begin{abstract}
Since the early days of dendrimer chemistry, mass spectrometry has been an important analytical method for determining the purity and the detection of defects in dendrimers. Meanwhile, growing evidence demonstrates the great potential of mass spectrometry for the investigation of non-covalent dendritic host-guest complexes. Mass spectrometry provides an efficient means to isolate them in the high vacuum inside a mass spectrometer under environment-free conditions. Gas-phase chemistry is particularly beneficial for exploring the intrinsic properties which cannot easily be studied in solution. This mini-review highlights the versatility of gas phase chemistry for (1) screening the specificity and stability of multivalent dendritic host-guest complexes depending on the nature of the guests, (2) revealing a dendritic effect during dendrimer-tweezer complex fragmentation, and (3) monitoring an intracomplex movement of small guests along the dendrimer periphery.
\end{abstract}

Keywords: host-guest chemistry; supramolecular chemistry; dendrimers; mass spectrometry; gas-phase chemistry; molecular mobility 


\section{Introduction}

The field of host-guest chemistry of dendritic molecules has grown into a special area of supramolecular chemistry during the last decades (1-2). The highly branched architectures of dendrimers endow them with unique recognition properties, which are appreciated for constructing diverse supramolecular host-guest systems. Insight into these systems opens up new opportunities not only to understand the fundamental principles in biological process (3-4), but also to develop functional materials (5-7).

Some ten to fifteen years ago, there was still a debate, whether dendrimers would form specific host-guest complexes at all. Meanwhile it is well known that they do: POPAM dendrimers have not only shown to bind metal ions, but even exhibit an interesting kinetic behaviour in that metal ions quickly complex to the periphery and then need significantly longer to enter the dendrimer core (8). Dendrimers have also been equipped with specific binding sites in their peripheries, e.g. crown ethers (9), urea units (10), ferrocenyl (11) and carbohydrate groups (12). For drug delivery, coreshell particles are under intense investigation (13-15).

However, with the growing complexity of these systems, the dendritic hostguest complexes are often large in size and molecular mass, and often display a highly symmetrical arrangement of building blocks. Therefore it is often rather difficult to characterize their exact structures and to determine the stoichiometries of the hosts and guests involved. For a convincing analysis and characterization, usually a number of different instrumental methods need to be applied (16-17). Moreover, many researchers became aware of the often quite significant influence of the environment on the formation of dendritic host-guest complexes (18). They can be strongly affected by the presence of the solvent or counter-ions. Stability constants and thermodynamic parameters determined in solution are always influenced by solvent 
effects. The intrinsic interaction between host and guest is thus inevitably challenging to unravel.

For a long time, mass spectrometry was only considered as an important analytical method in dendrimer chemistry. In most laboratory research, mass spectrometry merely served as an excellent routine analytical tool to determine the purity and to analyze the defects of dendrimers in higher generations (19-21). However, increasing evidence indicates the utility of mass spectrometry to go far beyond the mere analytical characterization. The gas phase inside the mass spectrometrer has proved to be particularly beneficial for the analysis of weakly bound host-guest complexes (22-26). The high vacuum inside a mass spectrometer provides an efficient means to isolate the complexes and to suppress the highly dynamic guest exchange equilibria in solution. Once the desired complex ions are generated, mass selection becomes possible and a large variety of tandem MS (MS/MS) experiments is available which enable the dendrimer chemist to examine the ions under environment-free conditions. Valuable information of the intrinsic features of the complexes as well as the reactivity of non-covalent species can be obtained. A comparison of these data from the gas phase, i.e. the intrinsic properties, with results from condensed phase, i.e. the properties as influenced by the environment, can consequently contribute significantly to the understanding of noncovalent bonds, and in return to guide the design of supramolecular host-guest system.

The objective of this mini-review is to highlight an emerging area by discussing studies which use tandem mass spectrometry to investigate dendrimerguest complexes. It advertises the great potential of gas-phase studies for dendrimer host-guest chemistry of dendrimers. We will focus on three different aspects: The first part will discuss a gas-phase approach to screen the relative binding strengths of 
multiple small molecule guests that can bind to the dendrimer periphery in a dynamic library. These gas-phase studies elegantly allow to compare different guests each of which is bound in a multivalent fashion to more than one binding site in the dendrimer. In the second example, dendritic viologen-tweezer complexes represent another type of dendrimer host-guest structure in which the complexation occurred at the core. In contrast to the solution behaviour, a quite pronounced dendritic effect is observed which has a major effect on the stability and on the fragment mechanisms of the viologen dications in the dendrimer core. The differences in the gas-phase behaviour of dendrimers of different generation can be traced back to backfolding of the dendrimer branches. Finally, we will discuss a "spacewalk" at molecular level. Crown ethers are able to walk along the periphery of POPAM dendrimers without intermediate dissociation. A quite simple hydrogen/deuterium exchange (H/D exchange) in the gas phase is capable of monitoring this highly dynamic intramolecular movement in the gas phase.

\section{Multivalency in the gas phase: multiple guest binding to urea-terminated POPAM}

\section{dendrimers}

Recently, dendrimers are gaining popularity as frameworks for the study of multivalent interactions in biological systems $(4,27)$. A particularly interesting example is the third generation POPAM dendrimer D (Figure 1), which carries 16 peripheral adamantylurea groups (28). As shown in Figure 2, dendrimer D can serve as the host scaffold for guests that can be bound through multivalent interaction. After an initial proton transfer from the guest acid group to the dendrimer's tertiary amines, strong electrostatic interactions exist between the acid anion of the guest molecule and 
the tertiary ammonium ions incorporated in host $\mathbf{D}$. In addition, multiple hydrogen bonds between the urea units of guest and host support binding. Therefore, host $\mathbf{D}$ enables a variety of guest molecules based on urea-acid structures to attach on its surface, even including some oligopeptides such as T (29). The most intriguing feature of such a multivalent system is the non-covalent decoration of dendrimer surface, giving rise to a dynamic binding equilibrium in solution, in which the guests can compete with each other and the guest with the optimal binding motif can easily be detected. Moreover, due to the multibranched structures of dendrimers, a dynamic combinatorial library of different complexes with various stoichiometries can consequently form when at least two different guests compete for binding to the dendrimer. Consequently, the multivalency of dendrimers surface is capable of attaching multiple drug molecules, targeting groups and solubilizing moieties coordinately (30).

Although the concept to dynamically modify the periphery of dendrimers is very attractive, the characterization of such a system seems to be a quite challenging task. Because up to eight of guests can bind to the same dendrimer in a dynamic manner, the determination of binding stoichiometries for complexes, in particular in a dynamic library with more than one type of guest is rather difficult. (28) 

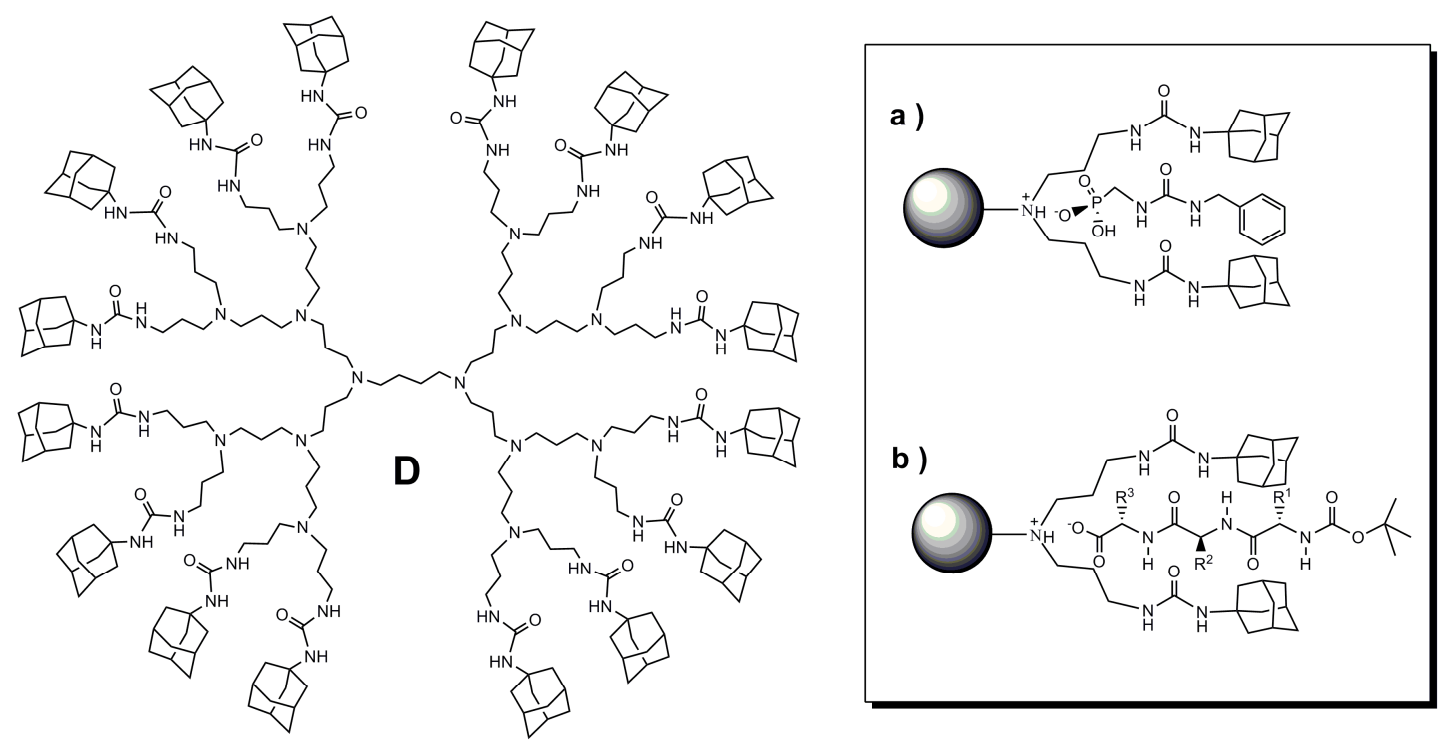<smiles>O=C(O)CNC(=O)NCc1ccccc1</smiles>

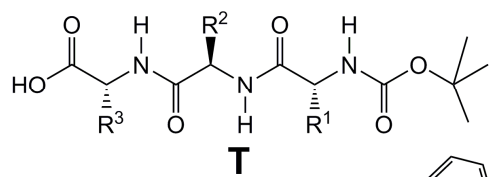<smiles>O=C(CNc1ccccc1)NCc1ccccc1</smiles>

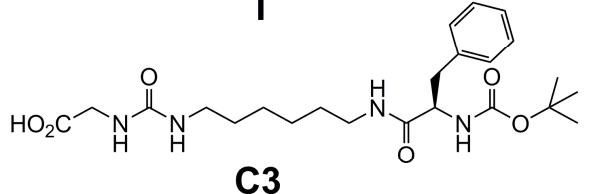<smiles>CCOc1cc(C(=O)OCCCCCNC(=O)NCC(=O)O)cc(OCC)c1OCCO</smiles><smiles>CCOc1cc(C(=O)OCCCCCCCCCO)cc(OCC)c1OCCO</smiles><smiles>CCOc1cc(C(=O)OCCCCCNC(=O)NCPO)cc(OCC)c1OCC</smiles><smiles>CCOc1cc(C(=O)OCCCCCCCCC(=O)O)cc(OCC)c1OCC</smiles><smiles>CCOc1cc(C(=O)OCCCCC[Si])cc(OCC)c1OCCO</smiles><smiles>CCOc1cc(C(=O)OCCCCCCCCO)cc(OCC)c1OCCO</smiles>

Figure 1. Top left: Third-generation POPAM dendrimer $\mathbf{D}$ with 16 peripheral admantylurea groups. Top right: The postulated binding mode of a dendrimer host with (a) a urea-substituted phosphonate; (b) an N-terminal Boc-protected tripeptide. Bottom: A variety of guests including urea-containing guests U1, U2, C1, P1, and S1. The three guests $\mathbf{C 2}, \mathbf{P 2}$, and $\mathbf{S 2}$ lack the urea group and thus serve as reference compounds for examining the binding mode. The Boc-protected tripeptides $\mathbf{T}$ (BocGGG, Boc-GGA, Boc-AAA, Boc-FGG, Boc-FFF, and Boc-GVV) were also investigated in the gas phase $(\mathrm{G}=$ glycine, $\mathrm{A}=$ alanine, $\mathrm{F}=$ phenylalanine, $\mathrm{V}=$ valine, Boc $=$ tert-butoxycarbonyl). 


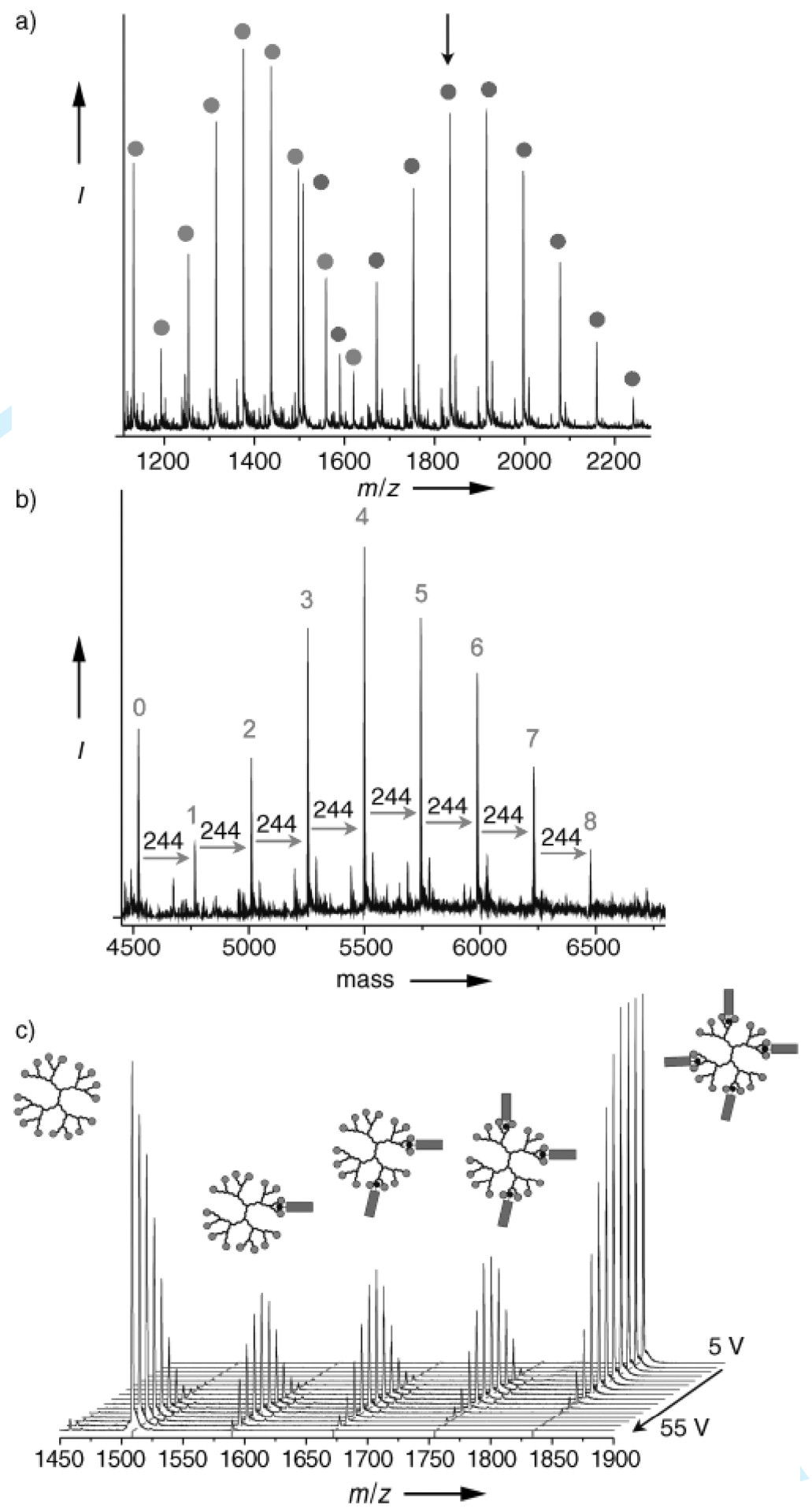

Figure 2. (a) ESI-FTICR mass spectrum of a sample of dendrimer $\mathbf{D}$ with six equivalents of guest $\mathbf{U} 2$. Two species ions of host-guest complexes with 4+ and 3+ charge states are observed respectively. (b) The deconvoluted mass spectrum shows complexes $\left[\mathbf{D} \bullet(\mathbf{U} 2)_{\mathrm{n}}\right]$ with $\mathrm{n}=0-8$. The mass differences of $\Delta \mathrm{m}=244$ correspond to individual guests $\mathbf{U 2}$. (c) CID mass spectrum of mass-selected $\left[\mathbf{D} \bullet(\mathbf{U} 2)_{4}\right]^{3+}$. At increasing collision energies, the guest molecules are successively removed as neutral molecules, finally only bare dendrimer ions are left. Reproduced from ref. 31 with kind permission from Wiley-VCH and the authors. 
Meijer and coworkers have studied the multivalent interaction between host $\mathbf{D}$ and a series of guest molecules by mass spectrometry (31-32). The transfer of dendrimer $\mathbf{D}$ and its host-guest complexes into gas phase is easily achieved by electrospray ionization mass spectrometry (ESI-MS). A small amount of acetic acid is added to the sample solution to achieve a net protonation of the dendrimer complexes. Figure 2a shows the ESI spectrum of, for example, a mixture of dendrimer $\mathbf{D}$ with six equivalents of guest $\mathbf{U} \mathbf{2}$ in chloroform. The complexes appear in charge states $3+$ and 4+. For each charge state, all possible assemblies $\left[\mathbf{D} \bullet(\mathbf{U} 2)_{n}\right]^{3+/ 4+}$ with $n=0-8$ are detected. Deconvolution of the different charge states provides a simpler and cleaner picture (Figure 2b). Apart from the naked dendrimer $\mathbf{D}$, eight peaks at higher mass correspond to the dendrimer with one to eight guest molecules bound to it. Each mass difference of $\Delta \mathrm{m}=244$ between two adjacent signals corresponds to one $\mathbf{U} \mathbf{2}$ guest molecule. The ESI-MS experiments unambiguously identify the individual complexes. Similar spectra are observed for the other guests listed in Figure 1.

Once the desired complex ions are transferred successfully into the gas phase, the stability of the ions of interest can be probed with tandem MS techniques, for example by fragmenting them in collision-induced dissociation (CID) experiments. After mass selection of the desired ions, the ions are accelerated, and subsequently collided with a neutral gas in the analyzer cell of a Fourier-transform ion-cyclotronresonance (FTICR) mass spectrometer. During the collision, part of the kinetic energy of the ions is converted into rovibrational excitation, which eventually gives rise to the fragmentation with the weakest bond to represent the most probably cleavage site. Figure $2 \mathrm{c}$ shows the detailed fragmentation picture of the $\left[\mathbf{D} \bullet(\mathbf{U} 2)_{4}\right]^{3+}$ complex. At increasing collision energies, the guests attached to the dendrimer can be removed as neutral molecules one after the other until finally free $\mathbf{D}$ ions are left. 
In the experiments described so far, all guests in the complexes under study were identical. No drastic change of the dissociation energies is thus expected, unless the guests interact with each other. However, when mixed complexes are treated the same way, a ranking of binding strengths in the gas phase can be obtained. Detailed insight into the influence of the guest structure on the binding strength may provide information about the binding mode. All guests in Figure 1 form complexes except for C2 (32), which lacks both the urea units and a strongly acidic end group. The fact that the urea groups are not mandatory for complex formation indicates that the attractive electrostatic interactions between the guests' phosphonate or sulphonate groups and the tertiary ammonium in the dendrimer's binding pockets are strong enough to generate host-guest complexes with $\mathbf{D}$. For the weaker carboxylic acid guests, the urea group is nevertheless required. This might indicate that no ion pair is formed between host and guest. Instead, hydrogen bonding is likely responsible for guest binding. Competition experiments are possible, when heterocomplexes are mass-selected and fragmented in the gas phase. The guest which is more readily expelled from the complex is the more weakly bound guest. Such CID experiments can be performed with all possible guest pairs. The result is that guests are bound significantly more strongly when they contain the urea groups. Consequently, hydrogen bonding contributes its share to the binding energy. This finding is in excellent agreement with the trend in solution-phase association constants gained for model systems in chloroform and thus we conclude that binding mode to be the same in solution and in the gas phase.

Finally, the binding strengths of a set of oligopetides with BOC protected amino termini to the dendrimer were also examined. Already, slight structure differences in the tripeptides lead to significant changes the binding strengths. For 


\section{A remarkable dendritic effect: complexes of a molecular tweezer and dendritic} viologen dications

Viologens are doubly charged bipyridinium ions which possess a quite electrondeficient dicationic core. They are known to be good guests for molecular tweezer $\mathbf{T w}$ (33) with its extended aromatic systems (Figure 3). In dichloromethane, viologentweezer complexes are quite stable, which is also true when the viologen is decorated with Fréchet's benzylether dendrons on both sides. The tweezer is located at the central core and thus additional interactions of the aromatic rings within the dendrons with the outer convex side of the tweezer may occur particularly in larger generations.

Upon electrospray ionization of the G0 viologen salt in the absence of the tweezer, no bare $\mathbf{G 0}^{2+}$ dications could be detected. Only singly and doubly charged clusters are observed in which the positive charges are counterbalanced by a sufficiently high number of counterions. Density functional calculations for a simple 
model compound indeed predict the $\mathrm{C}-\mathrm{N}$ bond in the viologen dication to dissociate due to the strong charge repulsion once the dication is formed in free form. Therefore, the $\mathbf{G 0}^{2+}$ dication might be a short-lived metastable ion, which decomposes before it can be detected on the timescale of the FTICR mass spectrometric experiments. The two product ions, i.e. a singly substituted, singly charged bipyridinium ion and the corresponding benzyl cation, are indeed observed in the ESI mass spectrum. Besides cluster formation and fragmentation, $\mathbf{G} \mathbf{0}^{2+}$ has two other modes of avoiding being a naked dication: Deprotonation which occurs presumably at the benzylic position and one-electron reduction at the ESI spray capillary to yield the cation-radical.

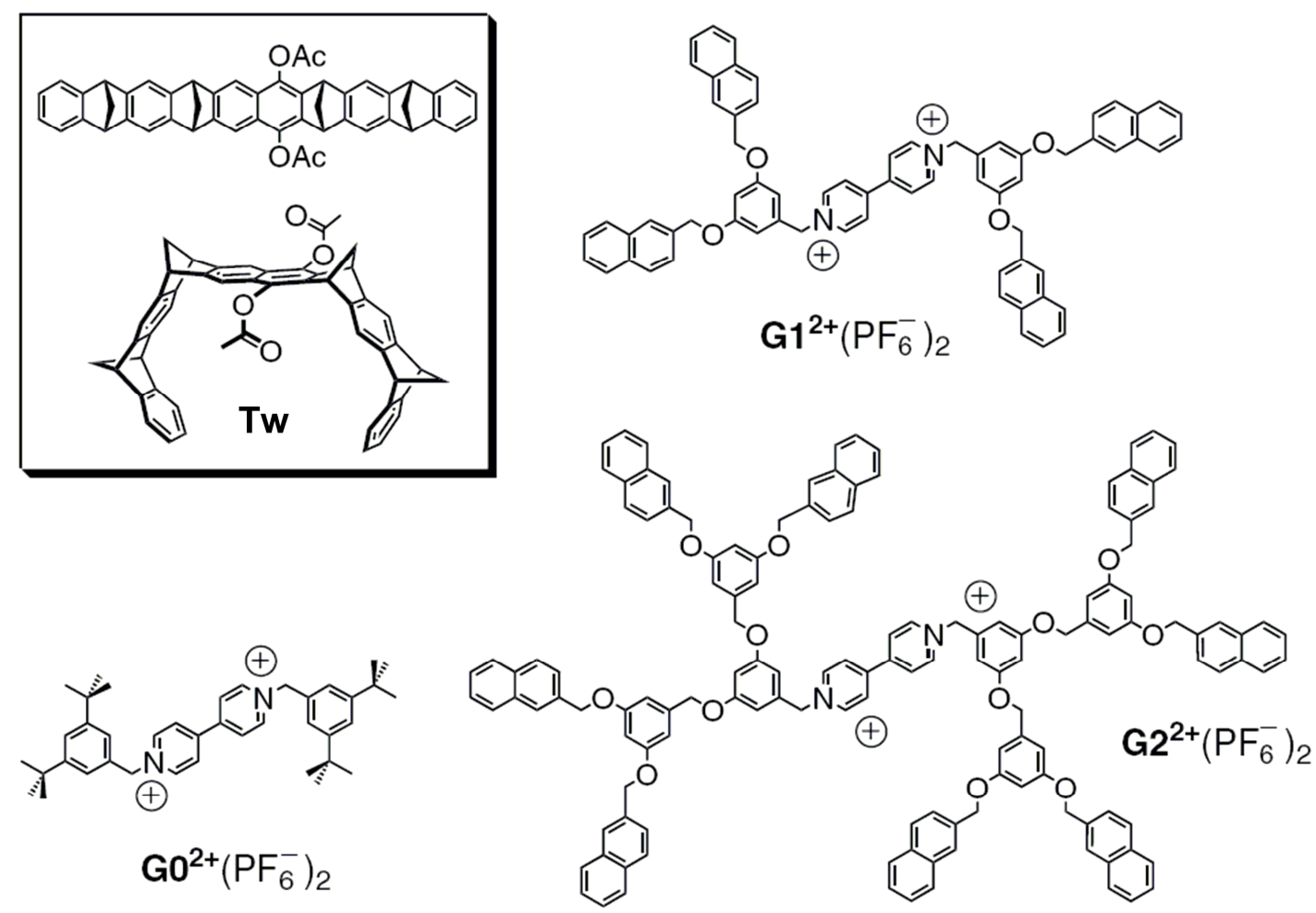

Figure 3. The detailed structures of the molecular tweezer $\mathbf{T w}$ (inset) and dendronsubstituted viologens $\mathbf{G} \mathbf{0}^{2+}, \mathbf{G 1}^{2+}$, and $\mathbf{G} \mathbf{2}^{2+}$.

In marked contrast, the generation of $\mathbf{G} \mathbf{1}^{2+}$ dications is possible, but only under as mild as possible ionization conditions. Finally, the generation of bare $\mathbf{G 2}^{\mathbf{2 +}}$ is 
even possible under somewhat harsher ionization conditions. Evidently, this marked change indicates a trend toward higher dication stability with increasing dendron size.

When one equivalent of the tweezer $\mathbf{T w}$ is added to the sample solutions, the mass spectra change dramatically (34). Even for the least stable $\mathbf{G} \mathbf{0}^{2+}$, quite intense signals correspond to the intact doubly charged 1:1 complexes are observed. The complexes also form as singly charged ions carrying one counterion. However, the mere existence of the complex dication shows the tweezer to stabilize the dications significantly through charge-transfer interaction. Simultaneously, this reduces the strong charge-repulsion effects and thus renders the complex detectable as a free dication. Similarly, dicationic tweezer-dendrimer complexes can be obtained for the larger generations.

For an analysis of the fragmentation behavior of the viologen-tweezer complexes, the desired ions were mass-selected and subjected to a CID experiment. When monoisotopic tweezer-G0 $\mathbf{2}^{\mathbf{2 +}}$ dications were isolated and examined, one would probably expected to see an initial loss of the tweezer followed by an immediate consecutive fragmentation of the remaining metastable dication (bottom pathway in Figure 4). Indeed, the two expected fingerprint fragments from $\mathbf{G 0}^{2+}$ are observed (Figure 5). However, an additional fragment at m/z 1059 corresponds to a singly charged tweezer-bipyrindium ion and clearly indicates the loss of a di-t-butylbenyzl cation from the complete complex to be operative in the fragmentation of $[\mathbf{T w} \cdot \mathbf{G 0}]^{2+}$. Clearly, it is also possible that the supramolecular interaction is stronger than the covalent N-benzyl bond. This finding raises the question, which of the two pathways shown in Figure 4 contributes to what extent. A double resonance experiment provides the answer: In this experiment, the ions with $\mathrm{m} / \mathrm{z} 1059$ are constantly removed from the FTICR analyzer cell during the whole duration of the MS/MS 
experiment and thus all consecutive fragments formed through this ion as an intermediate should vanish as well. The comparison of Figures 5a and 5b clearly shows that almost all of the bipyridinium cations at $\mathrm{m} / \mathrm{z} 359$ vanish in the double resonance experiment and thus must be due to a consecutive fragmentation through the intermediate complex at $\mathrm{m} / \mathrm{z}$ 1059. Instead, loss of tweezer followed by Coulomb explosion of the $\mathbf{G} \mathbf{0}^{2+}$ dication contributes at best a few percent to the bipyridinium fragment at $\mathrm{m} / \mathrm{z} 359$. This experiment clearly identifies the upper fragmentation channel in Figure 4 to the major one in the dissociation of the $[\mathbf{T w} \cdot \mathbf{G 0}]^{2+}$ complex. The covalent benzylic $\mathrm{C}-\mathrm{N}$ bond is thus weaker in this complex than the supramolecular interaction between host and guest.

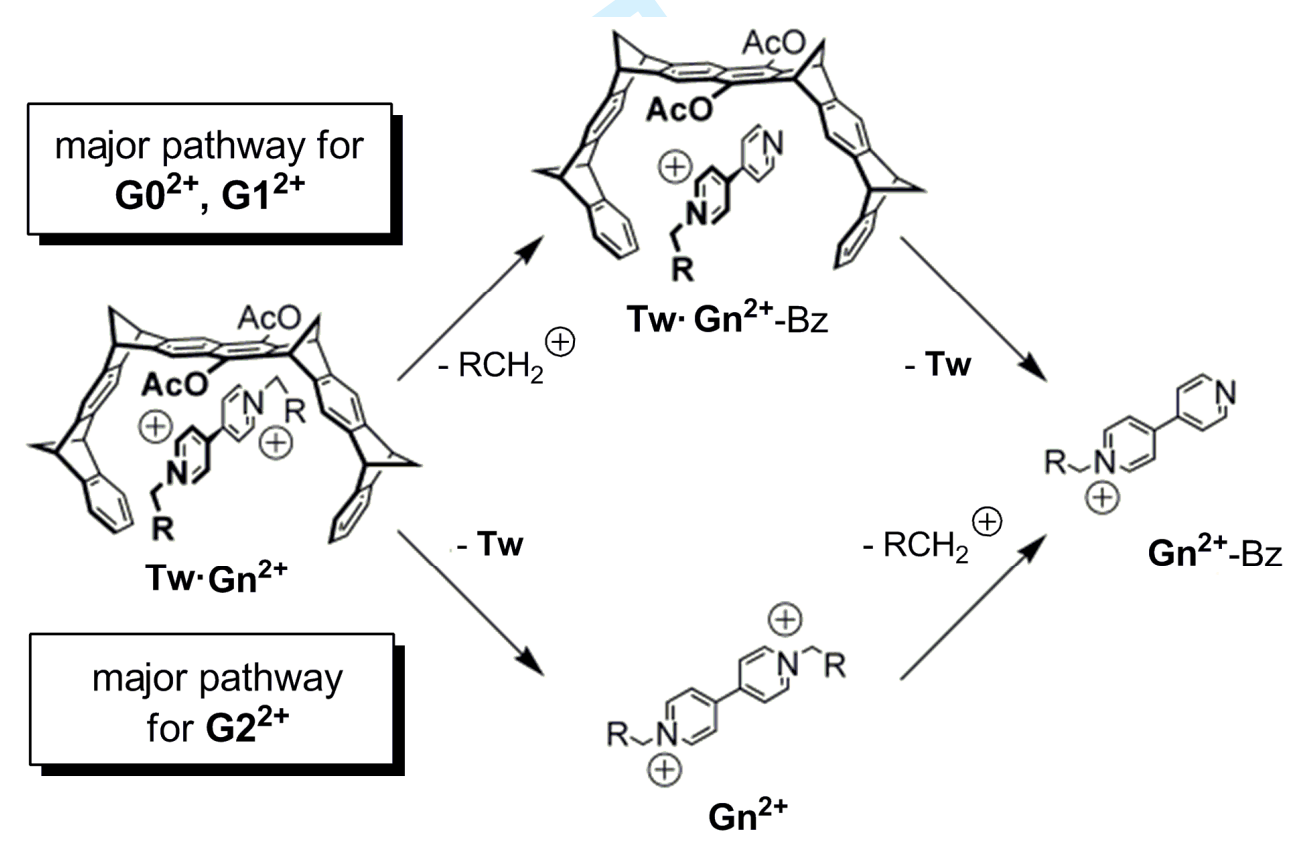

Figure 4. Two possible pathways for the fragmentation of the tweezer-viologen complexes. The reactivity switches from the upper to the lower pathway depending on the dendron sizes. 

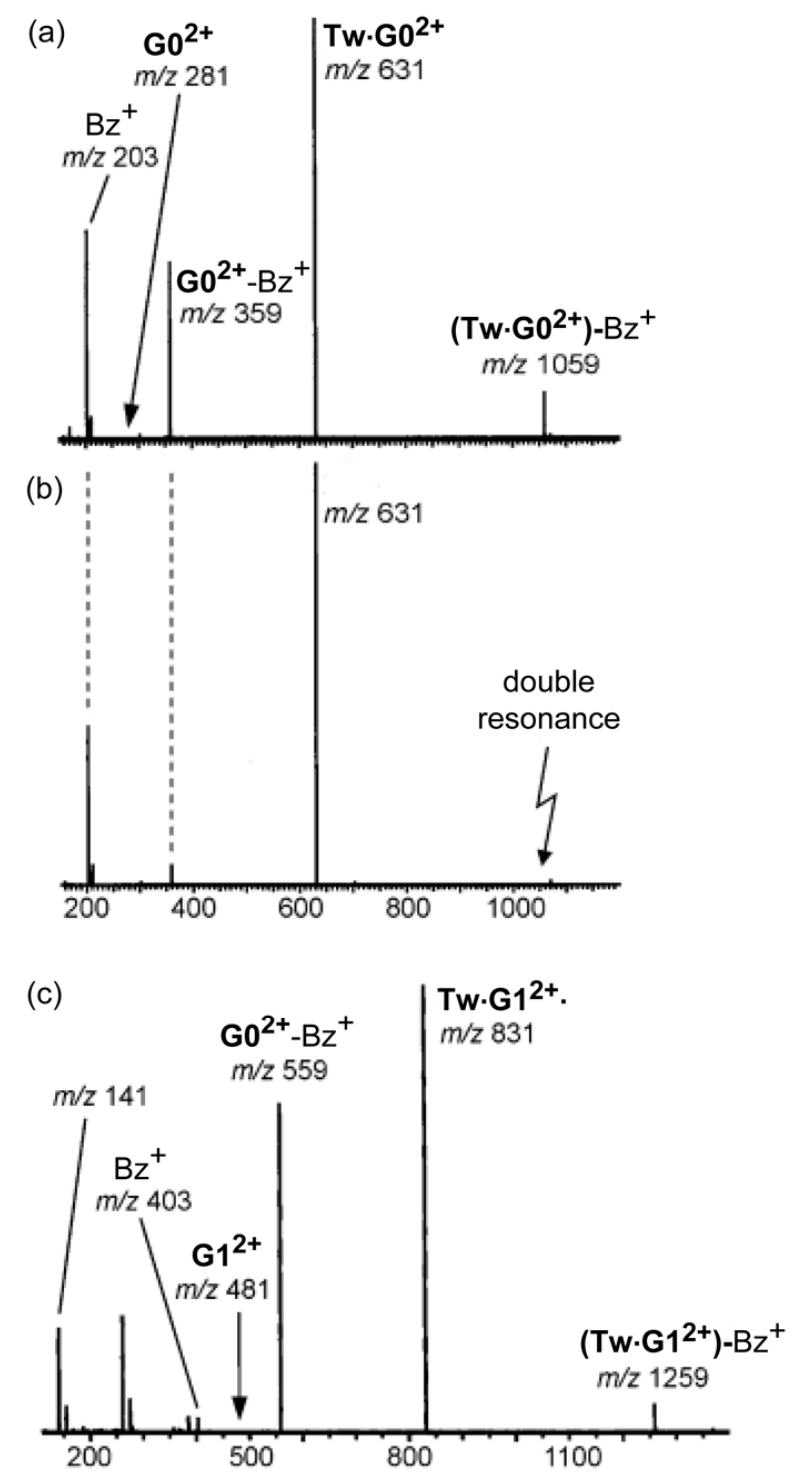

(d)

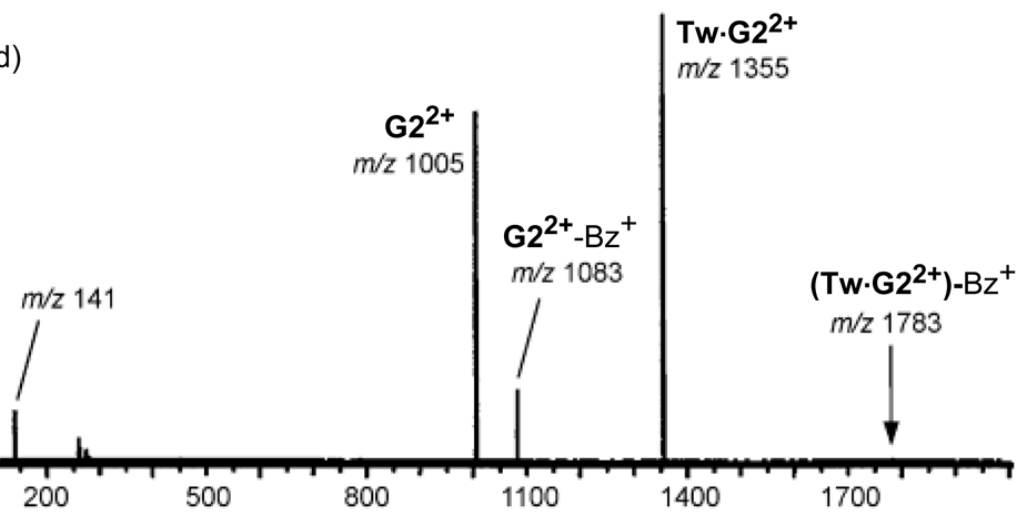

Figure 5. (a) Collision-induced decomposition (CID) of mass-selected tweezer-G0 $\mathbf{2}^{2+}$ complex. (b) Double-resonance experiment with the same ions, in which the fragment at $\mathrm{m} / \mathrm{z} 1059$ was ejected from the reaction cell during the whole experiment. (c) CID experiment with the tweezer- $\mathbf{G 1}^{2+}$ complex. (d) CID experiment with the tweezer$\mathbf{G 2}^{2+}$ complex revealing a complete change in reactivity. Tweezer loss is the major fragmentation pathway giving rise to dicationic $\mathbf{G 2}^{2+}$ at $\mathrm{m} / \mathrm{z} 1005$. 
The same reactivity pattern was also observed for the tweezer complex with $\mathbf{G 1}^{2+}$. However, the fragmentation behavior reversed for the complex with the $\mathbf{G 2}^{\mathbf{2 +}}$ viologen guest. Here, the loss of tweezer represents the first step and generates the bare $\mathbf{G} 2$ dication at m/z 1005, which can undergo further fragmentation by benzyl cation loss. The benzyl loss intermediate, however is not observed at all.

Consequently, the size of the dendrons plays an important role for the change in fragmentation behavior.
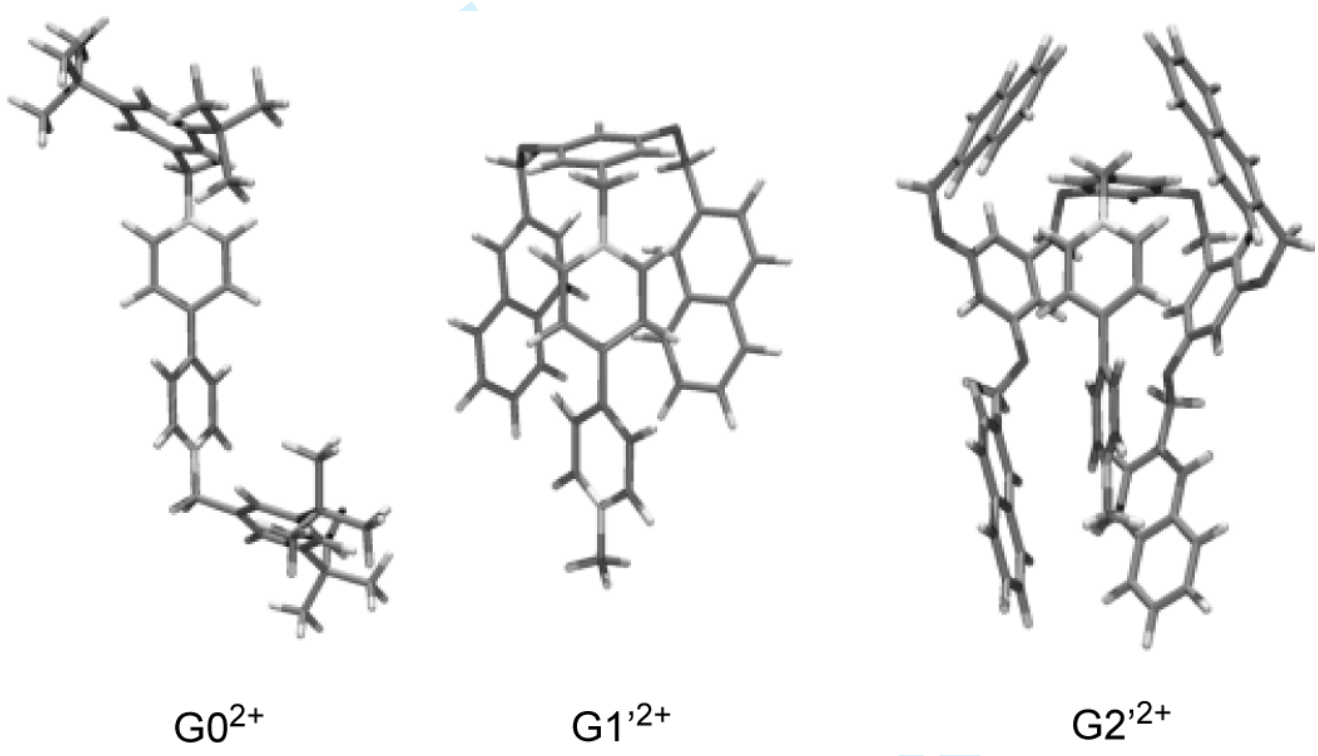

$\mathrm{G}^{\prime 2+}$

Figure 6. Lowest-energy conformations of the viologen derivatives substituted by two 3,5-di-t-butylbenzyl groups $\left(\mathbf{G 0}^{\mathbf{2}+}\right)$, by methyl and the $\mathbf{G 1}$ dendron $\left(\mathbf{G 1} \mathbf{2}^{\mathbf{2 +}}\right)$, and by methyl and the $\mathbf{G 2}$ dendron $\left(\mathbf{G 2}{ }^{, 2+}\right)$ calculated by Monte-Carlo conformer search using the MMFF force field implemented in SPARTAN 04. For the two larger structures, one dendron was replaced by methyl in order to reduce the necessary computer time.

At this point, we have encountered two interesting dendritic effects which need to be explained: (1) A clear trend in dication stabilities emerges: The larger the dendrons the better stabilized the dication is. (2) A reversal in the sequence of fragmentation steps occurs between $[\mathbf{T w} \cdot \mathbf{G 1}]^{2+}$ and $[\mathbf{T w} \cdot \mathbf{G} 2]^{2+}$. The origin of these dendritic effects can be traced back to the backfolding of branches in the larger 
dendrons which leads to self-solvation in the gas phase (Figure 6). For $\mathbf{G 0}^{2+}$, the relatively small benzyl substituents are unable to backfold into the vicinity of the dicationic viologen core. Consequently no self-solvation occurs and the cation remains unstabilized causing the instability of the benzyl-N bond. In $\mathbf{G 1}^{2+}$, the naphtyl methyl end groups can fold to approach the central viologen in a geometrically favorable manner. However, only a minor stabilization of the dication is achieved, since the naphthalene moieties are not very electron-rich. In contrast, $\mathbf{G 2}^{\mathbf{2 +}}$ is not only more flexible, but also provides the electron-rich, dihydroxybenzyl branching units which provide efficient internal solvation through the formation of intramolecular charge-transfer-complexes. The backfolding of dendrimer branches not only explains the dication stability order, but also the reversed fragmentation sequence of $[\mathbf{T w} \cdot \mathbf{G} 2]^{2+}$. The tweezer competes with the backfolded branches of the larger dendrons for the binding to the viologen. Consequently, the supramolecular interaction between tweezer and viologen decreases with increasing the dendron size. At the same time, the reduced charge repulsion stabilizes the covalent benzyl-N bond with increasing dendron size. For the complex of $\mathbf{G 2}^{2+}$, the covalent bond is finally stronger than the non-covalent interaction between host and guest.

The gas-phase experiments with the tweezer-dendrimer host-guest complexes add valuable insight into the reactivity of such species which cannot be gained from solution studies. In solution, not only solvent molecules change the properties of the complexes. Even more important, the counterions significantly stabilize the dications and reduce charge repulsion. Also, reversible binding which constantly leads to an exchange of the guest hampers the analysis of such a reaction. Such an exchange is not possible in the gas phase, because the complexes are isolated from each other in the high vacuum of a mass spectrometer. 


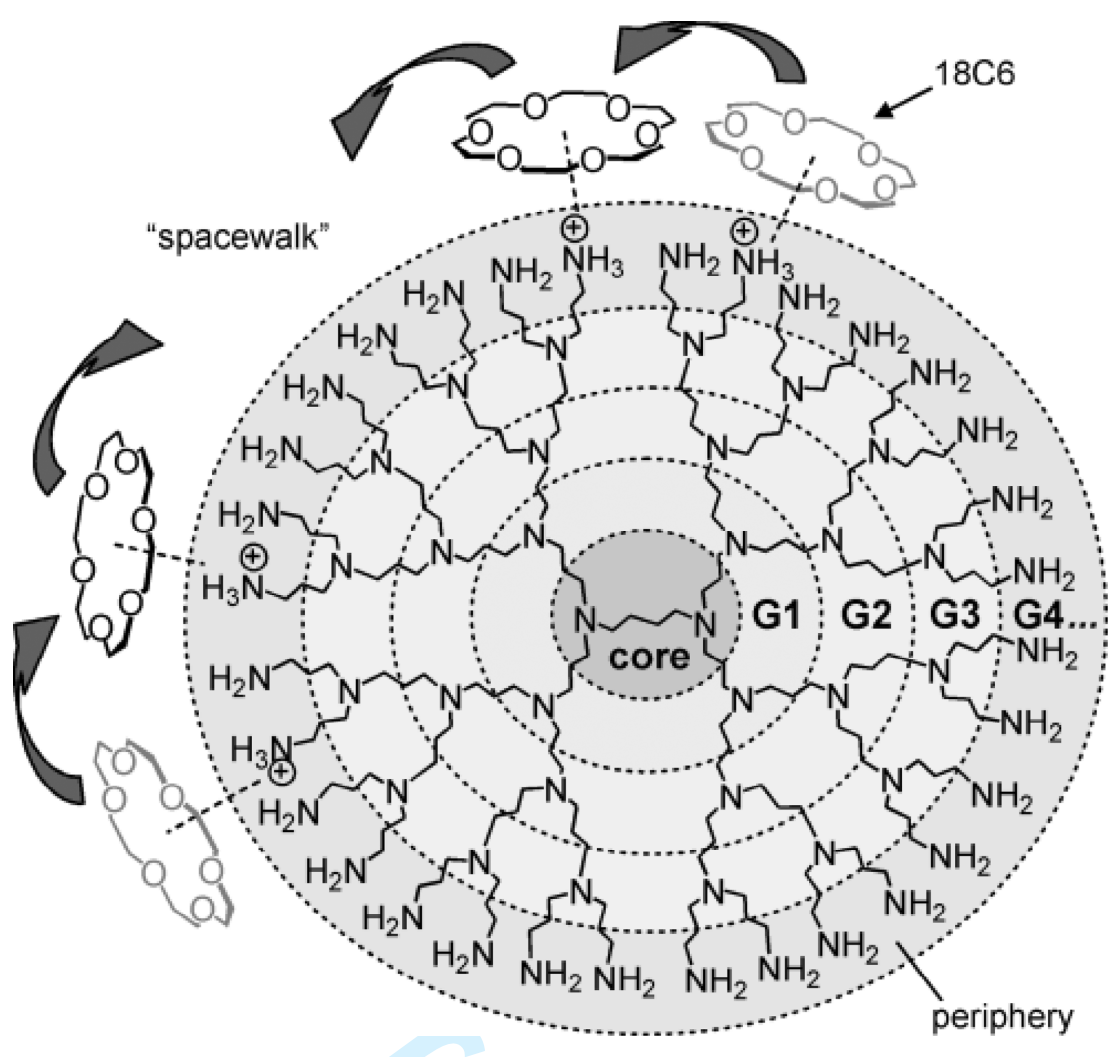

Figure 7. Schematic representation of crown ether movement along a G4 POPAM dendrimer.

\section{A molecular spacewalk: 18-Crown-6 walks along the periphery of POPAM dendrimers}

Molecular mobility has attracted considerable attention in supramolecular chemistry and biochemistry. Recently, a simple but challenging question (Figure 7) has been answered: Can 18-crown-6 travel on the surface of a POPAM dendrimer? Can they walk from binding site to binding site without intermediate dissociation (35-36)? Answering this question is difficult, if not impossible in solution, because the guest is always involved in dissociation/reassociation equilibria and intercomplex exchange. The critical issue of detecting such an intracomplex movement is to isolate the complexes from each other and from their free components. From the two preceding parts, one might assume the high vacuum of a mass spectrometry to be a good choice, 
since the gas phase is ideally suitable for studying the isolated complex. However, a simple mass analysis is obviously unable to provide direct evidence, as the intramolecular movement will not cause any mass change. Therefore, a gas-phase reaction is required as a probe, which must meet the following criteria: (1) It has to proceed energetically below the complex dissociation energy (for 18-crown-6 ammonium complexes ca. 180 - $200 \mathrm{~kJ} / \mathrm{mol}$ ), (2) must cause a mass change, and (3) needs to be directly linked to the guest movement. These requirements are met by a gas-phase H/D exchange reaction (37). 18-crown-6 (18C6) is well known to bind to primary ammonium ions in solution (38) as well as in the gas phase (39).

Furthermore, it efficiently protects the ammonium group to which it is attached against H/D exchange in the gas phase (40-41). Consequently, one would expect that a complete exchange of all labile hydrogen atoms in the dendrimer periphery is possible, if the crown ether moves around. Instead, 3 n hydrogen atoms should be protected against exchange in a dendrimer-crown complex containing $\mathrm{n}$ crown ethers, when the crown ether is positionally fixed.

Dendritic crown ether/ammonium complexes can easily be generated by ESI when a mixture of host and guest in methanol with $1 \%$ formic or acetic acid is sprayed. A broad charge state distribution (up to $\mathrm{z}=+8$ for G5) with various stoichiometries of crown molecule bound to dendrimer (up to $\mathrm{n}=5$ for G5) is observed. The H/D exchange experiments were carried out with complexes of $\mathbf{G 1}$ to G5 POPAM dendrimers. Figure 8a shows the H/D exchange results from G1. When there is no crown bound to singly protonated G1, all labile hydrogen atoms are rapidly exchanged. The exchange is almost complete after ca. $50 \mathrm{~ms}$. A doubly charged 1:1 complex which parallels the singly protonated POPAM since it also bears one free ammonium site, undergoes a similarly fast exchange. Already after $50 \mathrm{~ms}$, 
the whole isotope pattern has moved behind the threshold at which is would be expected to come to a halt when three protons were protected against exchange. Instead, a special case is encountered, when both ammonium sites are occupied by crown ethers: The exchange is almost completely suppressed. The last experiment shows that the exchange proceeds through a so-called (40-41) relay mechanism (Figure $8 \mathrm{~b}$ ). One ammonium site must remain unoccupied in order to permit a fast H/D-exchange process.

The same scenario is found up to G5 POPAM dendrimer complexes. The results for $\mathbf{G 2}$ are shown in Figure 8c, those obtained with G3 and G4 in Figure 9. The following $\mathbf{G 2}$ experiment further confirmed the exchange behavior observed in G1 (Figure 8c). These results clearly demonstrate the crown ethers to move quite rapidly along the dendrimer periphery.

Mechanistically, the crown ether spacewalk must proceed stepwise: A new hydrogen bridge is formed with a neighboring amine followed by the release of one to the old binding site. Then the next new hydrogen bond is formed and so on. A dissociation-reassociation mechanism can safely be excluded, because the crown ether would not return to the dendrimer once it has dissociated in the high vacuum inside the mass spectrometer. Similarly, a back-side attack mechanism with an intermediate in which both binding sites are fully bound is unlikely. This would require much longer alkyl chains between the two binding sites. So far, the mechanism is quite clear. One question, however, remains: Does the crown ether move as a neutral crown from one ammonium site to another ammonium site or does it move together with a proton from an ammonium to a neutral amino group? These two scenarios are shown in Figures 10a,b and can be resolved by H/D exchange experiments on 1,12diaminododecane as a model compound mimicking the dendrimer (Figure 10c). 

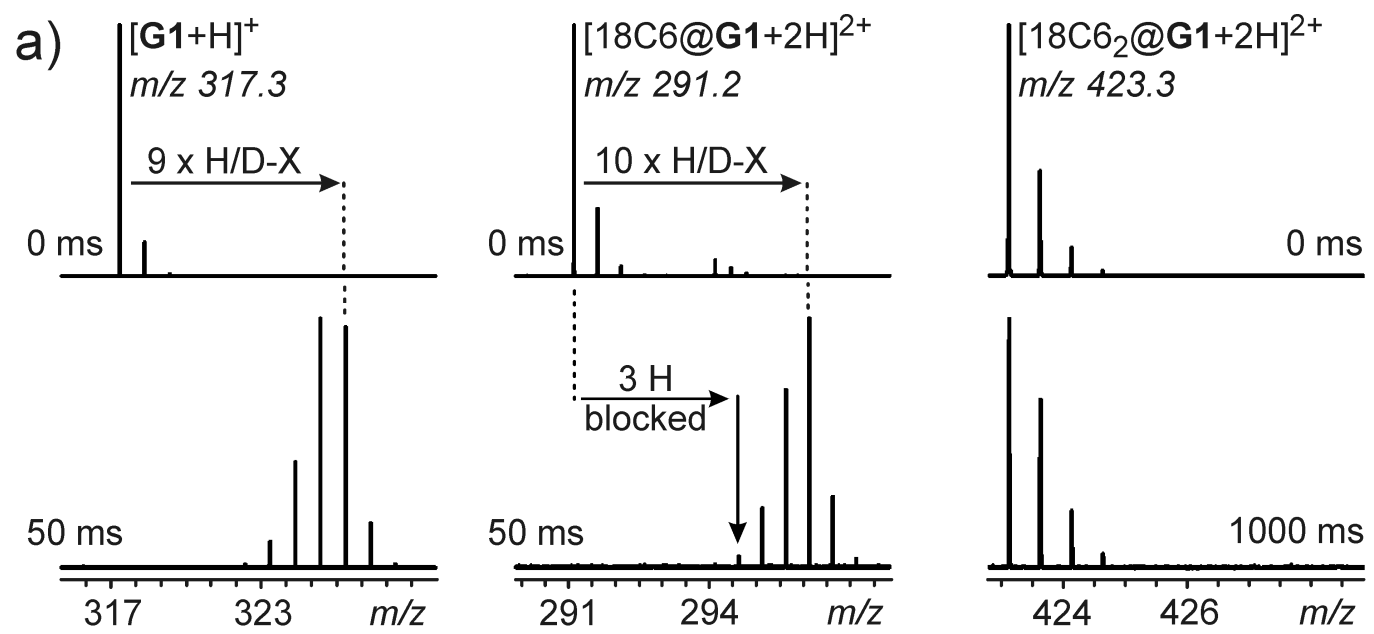

b)<smiles>CO[18O]</smiles><smiles>[R][NH+]([R])CCc1ccccc1CCN</smiles><smiles>[R]N([R])CCC1CCCCC1CCN[NH+]([R])OCOC</smiles><smiles>[R]N1CCCCCCCC1CC[N+](=[NH+])[NH-]</smiles>

$\mathrm{R}=$ peripheral branches

C) $\quad[18 \mathrm{C} 6 @ \mathbf{G} 2+2 \mathrm{H}]^{2+}$

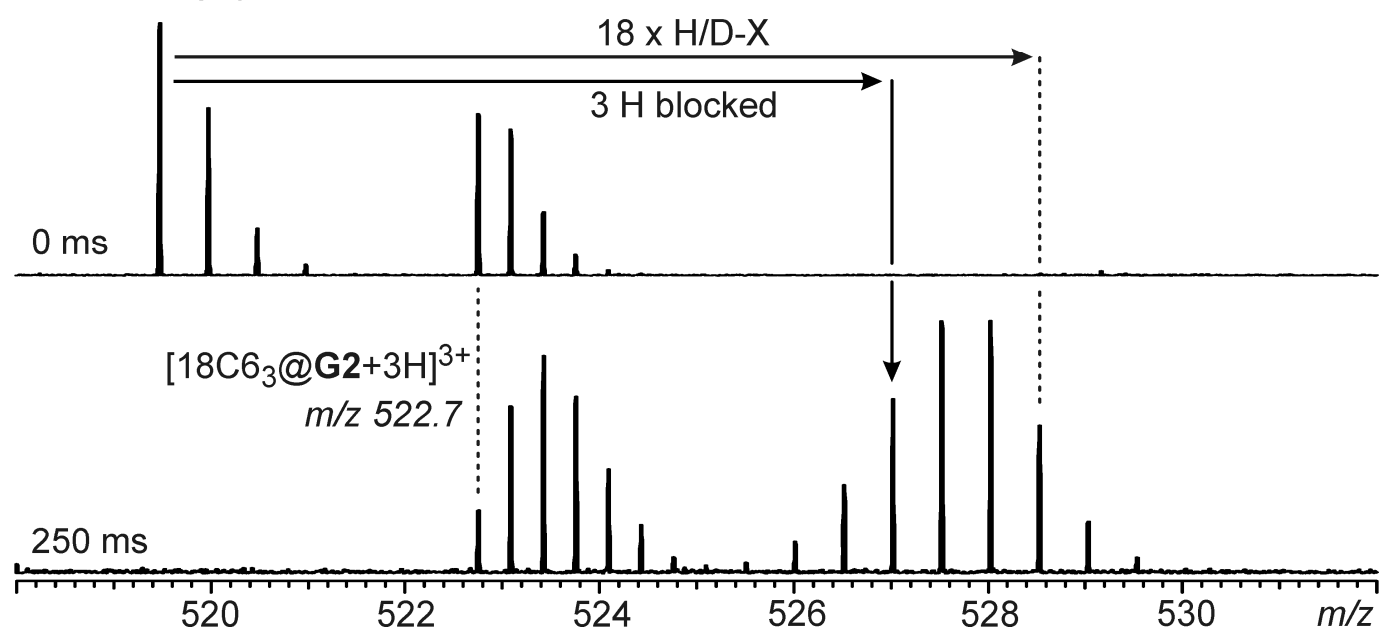

Figure 8. (a) Left: Left: H/D exchange experiment with singly protonated G1 (0 and $50 \mathrm{~ms}$ reaction time). Center: $\mathrm{H} / \mathrm{D}$ exchange of all ten $\mathrm{NH}$ protons of the doubly protonated 1:1 18-crown-6/G1 complex (0 and $50 \mathrm{~ms}$ ). Right: An extremely slow H/D exchange is observed for the doubly charged 2:1 18-crown-6/G1 complex (0 and 1000 ms). (b) A "relay" mechanism for the gas-phase H/D exchange at protonated POPAM dendrimers explains why the exchange is so slow in $\left[18 \mathrm{C} 6_{2} @ \mathbf{G} \mathbf{1}+2 \mathrm{H}\right]^{2+}$. (c) The same scenario is observed for higher generation dendrimers. 

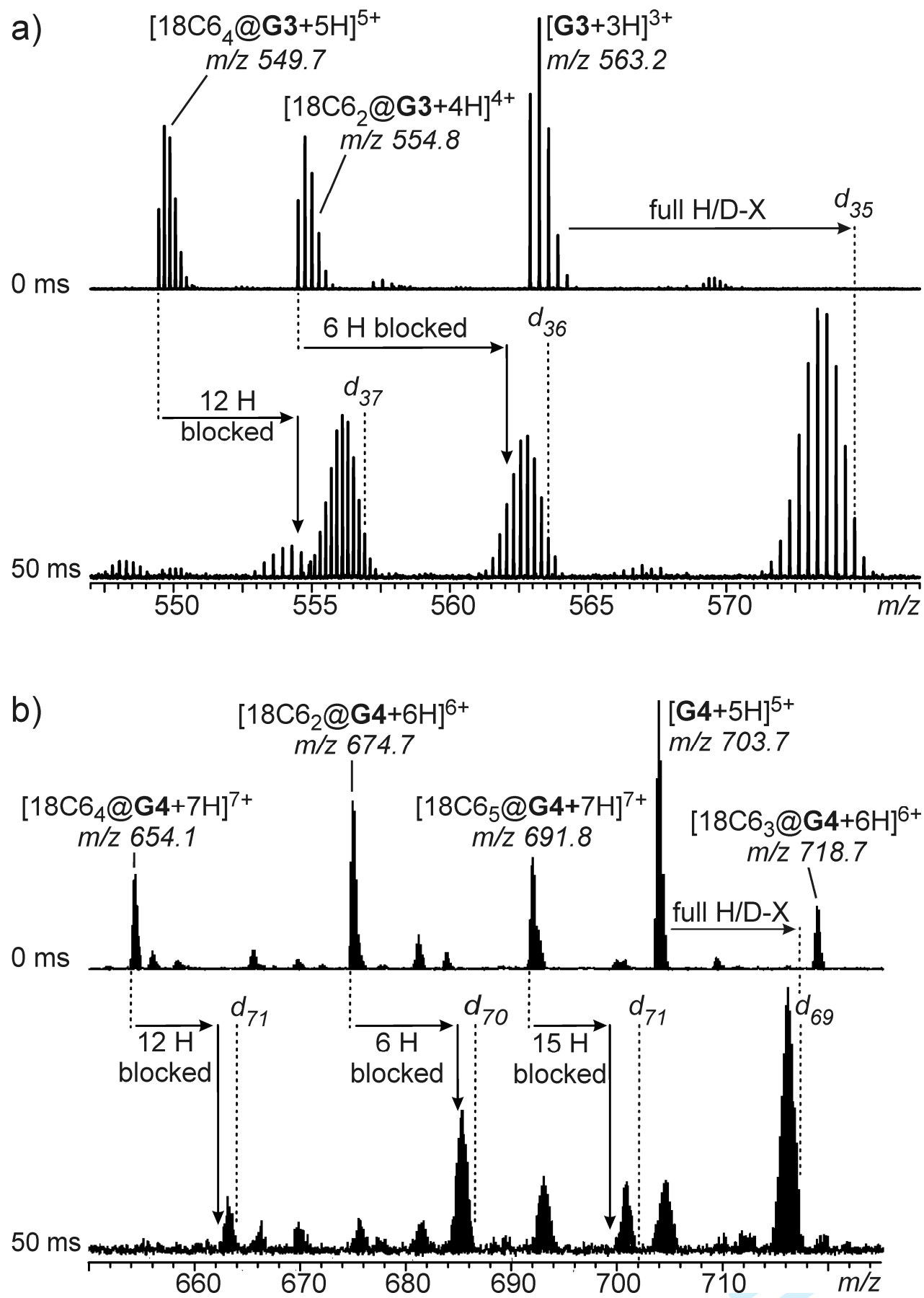

Figure 9. H/D exchange experiments conducted with 18-crown-6 complexes of (a) G3 and (b) G4 POPAM dendrimers. Already after $50 \mathrm{~ms}$, the exchange has proceeded beyond the positions at which it would be expected to stop, if the crown ethers would protect the ammonium protons against exchange (vertical solid arrows). Minor signals in the spectra are due to the typical defects in the dendrimer structure which unavoidably accumulate in the higher generations.

Now, the doubly protonated 1:1 complex bears two ammonium groups, one of which is bound to the crown ether. This corresponds to the situation in Figure 10a. 
Exchange of only three hydrogen atoms from the free ammonium ion would indicate the crown to be positionally fixed and rule out the ammonium-ammonium scenario. An exchange of all six protons would clearly show that a crown movement between two ammonium ions is indeed possible. The singly protonated 1:1 complex, instead, has one ammonium group carrying the crown ether and a free ammonium group and thus corresponds to the situation in Figure 10b. Exchange of only two protons would again indicate the crown to be fixed at the ammonium ion and would rule out the ammonium-to-amine scenario, while the exchange of all five protons would provide evidence for the transfer of a protonated crown ether. The result is clearcut: The doubly charged complex only exchanges three hydrogen atoms, while all five can be exchanged in the singly protonated complex. This clearly indicates a protonated crown ether to move from the ammonium to the amine terminus of the DAD chain. Likely, charge repulsion prohibits the ammonium-to-ammonium scenario.
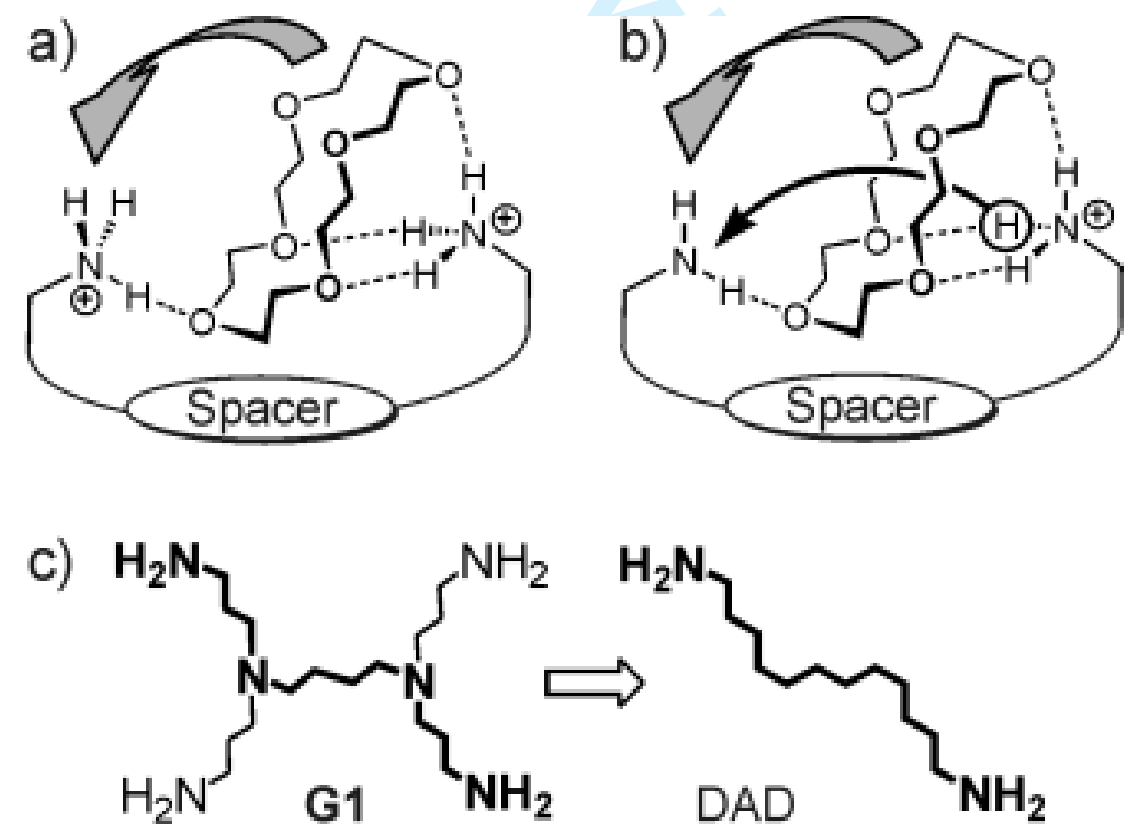

Figure 10. Two possible mechanisms for crown' spacewalk: (a) ammonium-toammonium scenario; (b) ammonium-to-amine scenario. (c) The model compound 1,12-diaminododecane (DAD). 


\section{Conclusions}

Three applications of tandem mass spectrometry in dendrimer host-guest chemistry show the versatility and the potential of this method: Stoichiometries can be determined. In competition experiments, the binding strengths of different guest can be compared and yield information on the binding mode. Comparison with the solution binding parameters may allow to draw conclusions on the similarities and the solvation-mediated differences. In particular, however, it is interesting to investigate the reactivity in the gas phase, because all dynamic host-guest exchange processes are suppressed in the gas phase. Consequently, only direct dissociation reactions or intramolecular processes can occur providing insight into a completely new reactivity which cannot easily be examined in solution. In our examples, the energetic issues are closely related to structural aspects as well as reactivity. Through a detailed analysis of fragmentation reactions and their relative energies, indications for backfolding could be obtained. With the help of bimolecular reactions, i.e. the H/D exchange with methanol-OD, insight into the intramolecular dynamics and molecular mobility in dendrimer guest complexes could be obtained.

\section{References}

(1) Baars, M.W.P.L.; Meijer, E.W. Top. Curr. Chem. 2000, 210, 131.

(2) Zimmerman, S.C.; Lawless, L.J. Top. Curr. Chem. 2001, 217, 95.

(3) Hecht, S.; Fréchet, J.M. Angew. Chem. 2001, 113, 76; Angew. Chem. Int. Ed. 2001, 40, 74.

(4) Martos, V.; Castreño, P.; Valero, J.; de Mendoza, J. Curr. Opin. Chem. Biol. 2008, 12, 698.

(5) Stiriba, S.E.; Frey, H.; Haag, R. Angew. Chem. 2002, 114, 1385; Angew. Chem. Int. Ed. 2002, 41, 1329.

(6) Longmire, M.; Choyke, P.L.; Kobayashi, H., Curr. Top. Med. Chem. 2008, 8, 1180.

(7) Majoros, I.J.; Williams, C.R.; Baker Jr., J.R. Curr. Top. Med. Chem. 2008, 8, 1165.

(8) Vögtle, F.; Gestermann, S.; Kauffmann, C.; Ceroni, P.; Vicinelli, V.; Balzani, V. J. Am. Chem. Soc. 2000, 122, 10398.

(9) Jones, J.W.; Bryant, W.S.; Bosman, A.W.; Janssen, R.A.J.; Meijer, E.W.; Gibson, H.W. J. Org. Chem. 2003, 68, 2385.

(10) Paleos, C.M.; Tsiourvas, D.; Sideratou, Z.; Tziveleka, L. Biomacromolecules 2004, 5, 524.

(11) Nijhuis, C.A.; Huskens, J.; Reinhoudt, D.N. J. Am. Chem. Soc. 2004, 126, 12266. 
(12) Ashton, P.R.; Boyd, S.E.; Brown, C.L.; Nepogodiev, S.A.; Meijer, E.W.; Peerlings, H.W.I.; Stoddart, J.F. Chem. Eur. J. 1997, 3, 974.

(13) Haag, R. Angew. Chem. 2004, 116, 280; Angew. Chem. Int. Ed. 2004, 43, 278.

(14) Svenson, S.; Tomalia, D.A. Adv. Drug Deliver. Rev. 2005, 57, 2106.

(15) Calderón, M.; Quadir, M.A.; Sharma, S.K.; Haag, R. Adv. Mater. 2010, 22, 190.

(16) Shcharbin, D.; Pedziwiatr, E.; Bryszewska, M. J. Control. Release 2009, 135, 186.

(17) Biricova, V.; Laznickova, A. Bioorg. Chem. 2009, 37, 185.

(18) Giansante, C.; Mazzanti, A.; Baroncini, M.; Ceroni, P.; Venturi, M.; Klärner, F.G.; Vögtle, F. J. Org. Chem. 2009, 74, 7335.

(19) Schalley, C.A.; Baytekin, B.; Baytekin, H.T.; Engeser, M.; Felder, T.; Rang, A. J. Phys. Org. Chem. 2006, 19, 479.

(20) Blais, J.C.; Turrin, C.O.; Caminade, A.M.; Majoral, J.P. Anal. Chem. 2000, 72, 5097.

(21) Hummelen, J.C.; Dongen, J.L.J.; Meijer. E.W. Chem. Eur. J. 1997, 3, 1489.

(22) Schalley, C.A.; Springer, A. Mass Spectrometry and Gas-Phase Chemistry of Non-Covalent Complexes. Wiley: Hoboken/NJ, 2009.

(23) Baytekin, B.; Baytekin, H.T.; Schalley, C.A. Org. Biomol. Chem. 2006, 4, 2825.

(24) Schalley, C.A. Mass. Spectrom. Rev. 2001, 20, 253.

(25) Weimann, D.P.; Schalley, C.A. Supramol. Chem. 2008, 20, 117.

(26) Schalley, C.A. Int. J. Mass Spectrom. 2000, 194, 11.

(27) Mulder, A.; Huskens, J.; Reinhoudt, D.N. Org. Biomol. Chem. 2004, 2, 3409.

(28) Baars, M.W.P.L.; Karlsson, A.J.; Sorokin, V.; Waal, B.F.W.; Meijer, E.W. Angew. Chem. 2000, 112, 4432; Angew. Chem. Int. Ed. 2000, 39, 4262.

(29) Boas, U.; Sontjens, S.H.; Jensen, K.J.; Christensen, J.B.; Meijer, E.W. ChemBioChem 2002, 3, 433.

(30) Galeazzi, S.; Hermans, T.M.; Paolino, M.; Anzini, M.; Mennuni, L.; Giordani, A.; Caselli, G.; Makovec, F.; Meijer, E.W.; Vomero, S.; Cappelli, A., Biomacromolecules 2010, 11, 182.

(31) Broeren, M.A.; van Dongen, J.L.; Pittelkow, M.; Christensen, J.B.; van Genderen, M.H.; Meijer, E.W. Angew. Chem. 2004, 116, 3579; Angew. Chem. Int. Ed. 2004, 43, 3557.

(32) Pittelkow, M.; Nielsen, C.B.; Broeren, M.A.; van Dongen, J.L.; van Genderen, M.H.; Meijer, E.W.; Christensen, J.B. Chem. Eur. J. 2005, 11, 5126.

(33) Klärner, F.G.; Kahlert, B. Acc. Chem. Res. 2003, 36, 919.

(34) Schalley, C.A.; Verhaelen, C.; Klärner, F.G.; Hahn, U.; Vögtle, F. Angew. Chem. 2005, 117, 481; Angew. Chem. Int. Ed. 2005, 44, 477.

(35) Winkler, H.D.; Weimann, D.P.; Springer, A.; Schalley, C.A. Angew. Chem. 2009, 121, 7382; Angew. Chem. Int. Ed. 2009, 48, 7246.

(36) Weimann, D.P.; Winkler, H.D.; Falenski, J.A.; Koksch, B.; Schalley, C.A. Nature Chem. 2009, 1, 573.

(37) Lifshitz, C. Int. J. Mass Spectrom. 2004, 234, 63.

(38) Cram, D.J.; Cram, J.M. Acc. Chem. Res. 1978, 11, 8.

(39) Maleknia, S.; Brodbelt, J. J. Am. Chem. Soc. 1993, 115, 2837.

(40) Lee, S.W.; Lee, H.N.; Kim, H.S.; Beauchamp, J.L. J. Am. Chem. Soc. 1998, 120, 5800.

(41) Wyttenbach, T.; Bowers, M.T. J. Am. Soc. Mass Spectrom. 1999, 10, 9. 

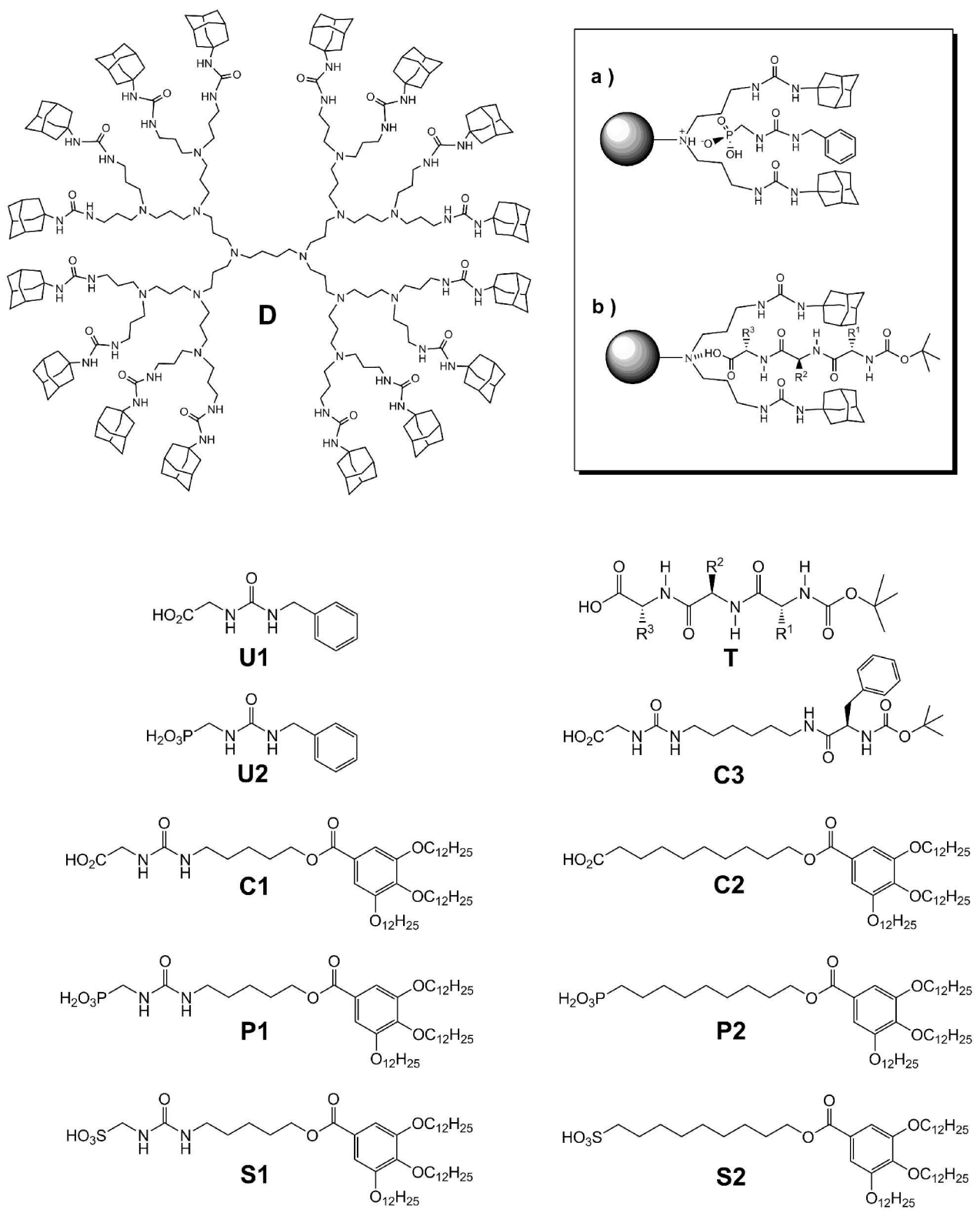

$166 \times 206 \mathrm{~mm}(600 \times 600 \mathrm{DPI})$

URL: http:/mc.manuscriptcentral.com/tandf/gsch Email: suprachem@mail.cm.utexas.edu 
a)

b)
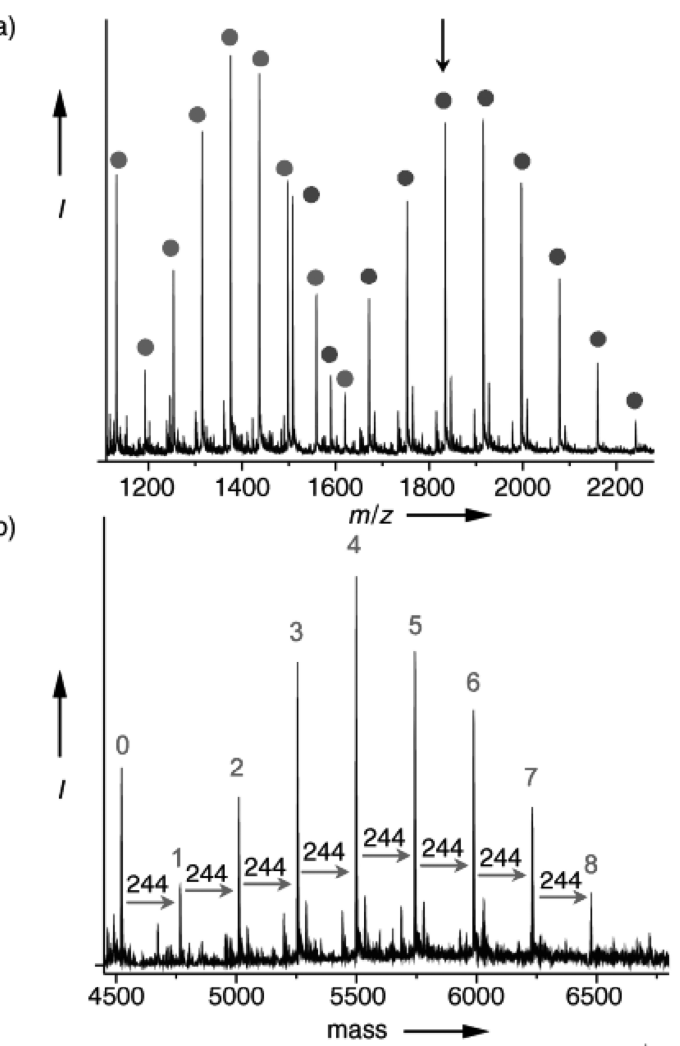

c) $176 \times 336 \mathrm{~mm}(600 \times 600 \mathrm{DPI})$ 


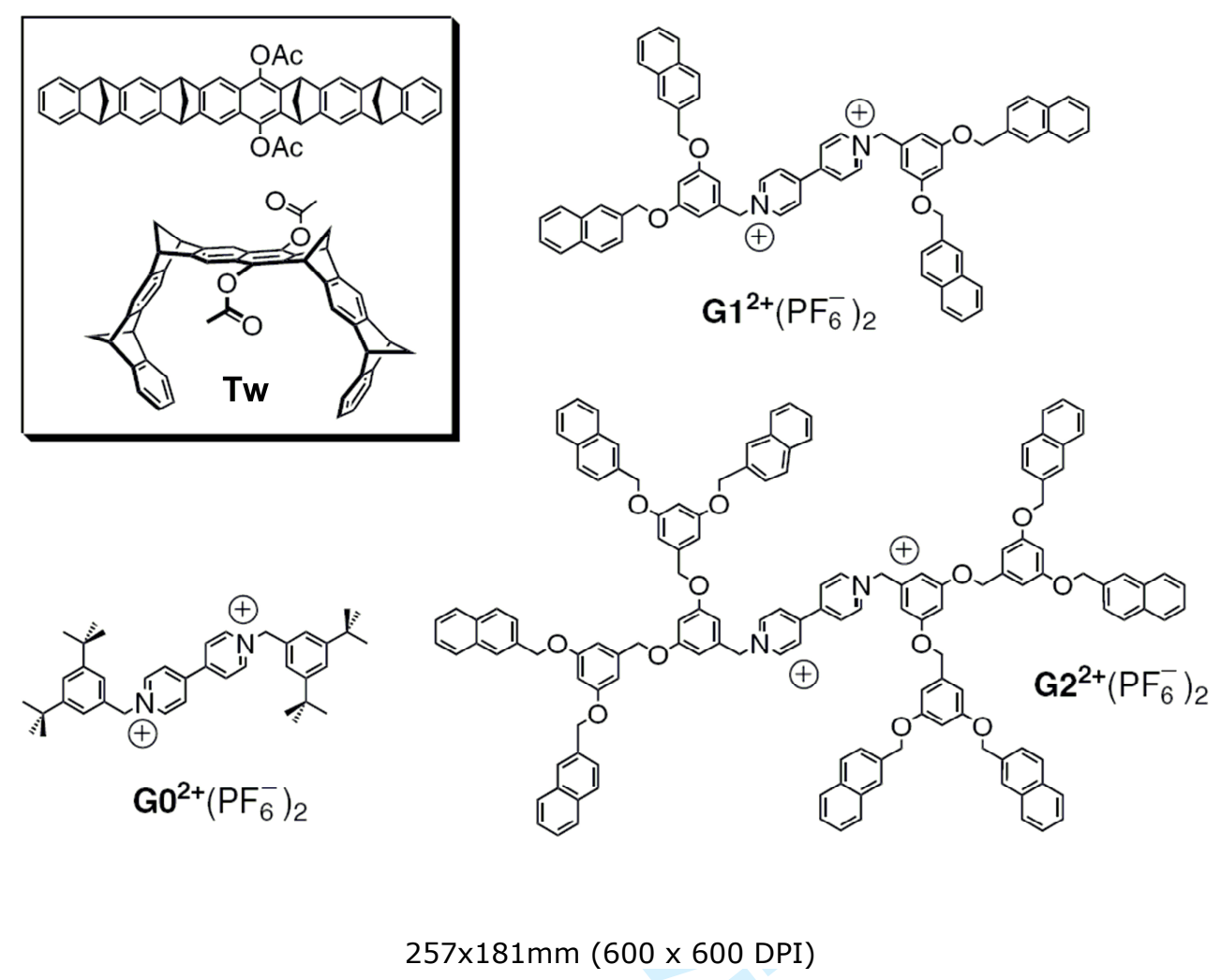

34

35

36

37

38

39

40

41

42

43

44

45

46

47

48

49

50

51

52

53

54

55

56

57

58

59

60

URL: http:/mc.manuscriptcentral.com/tandf/gsch Email: suprachem@mail.cm.utexas.edu 


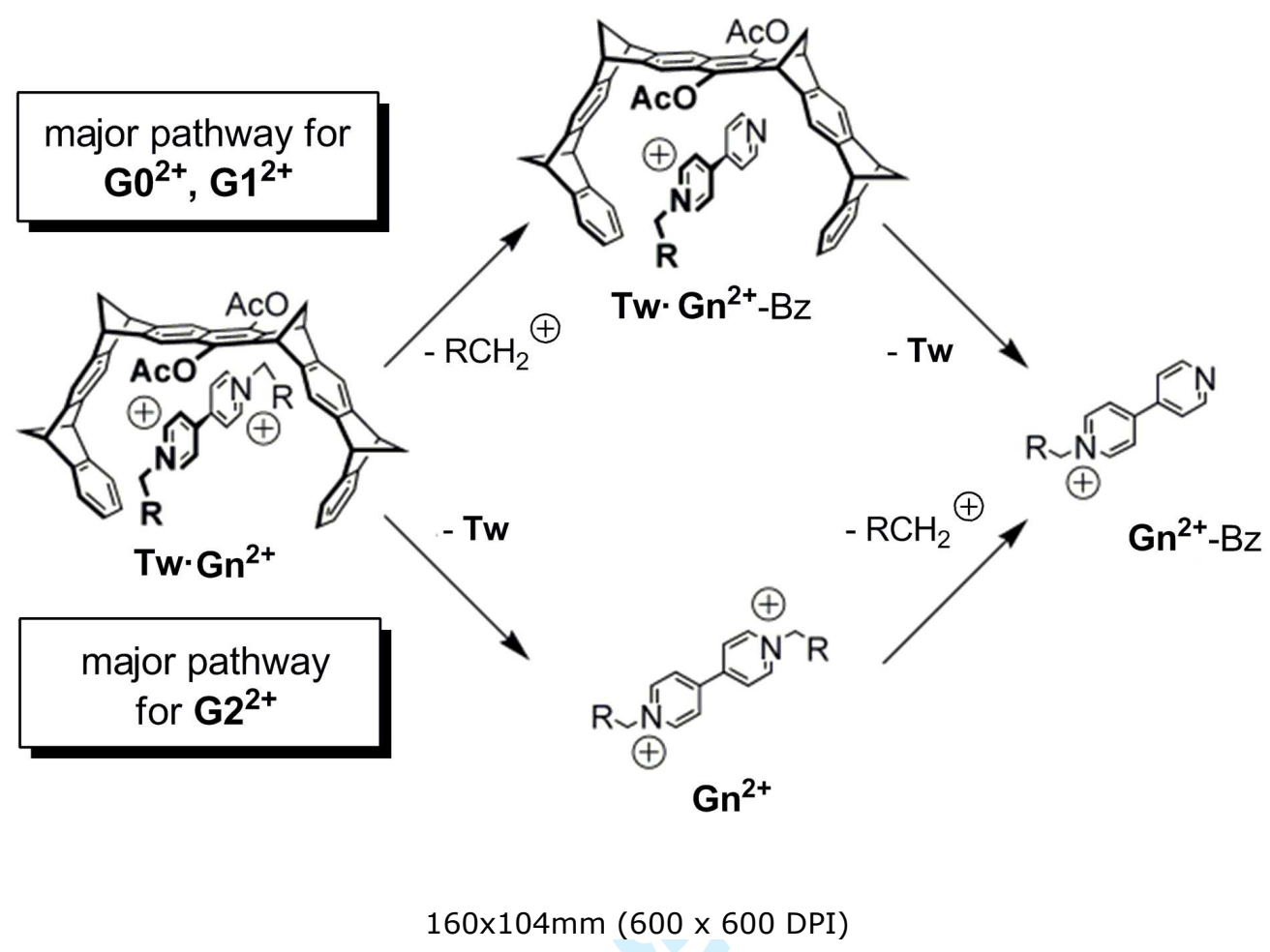




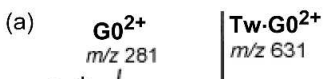




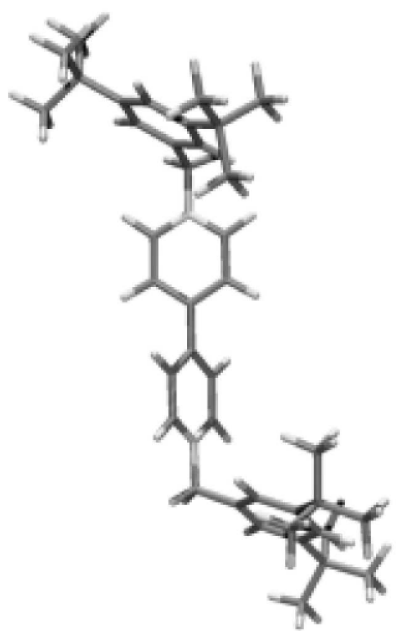

$$
\mathrm{GO}^{2+}
$$

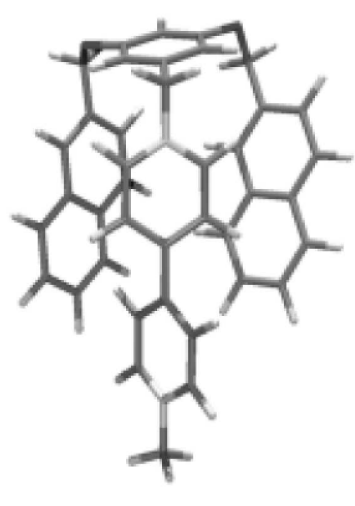

$$
\mathrm{G}^{\prime 2+}
$$

$177 \times 100 \mathrm{~mm}(600 \times 600 \mathrm{DPI})$

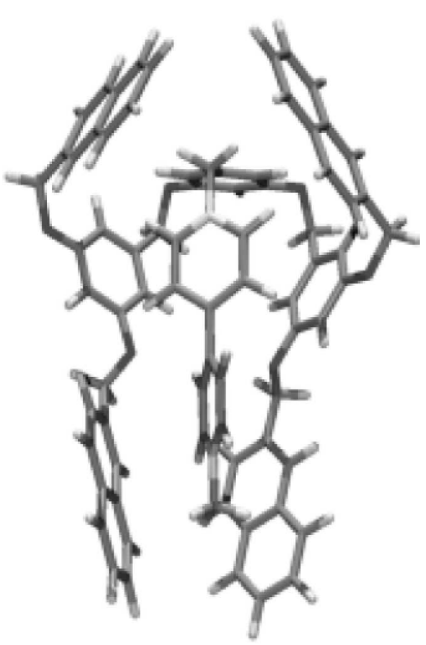

$\mathrm{G}^{, 2+}$

34

35

36

37

38

39

40

41

42

43

44

45

46

47

48

49

50

51

52

53

54

55

56

57

58

59

60

URL: http:/mc.manuscriptcentral.com/tandf/gsch Email: suprachem@mail.cm.utexas.edu 


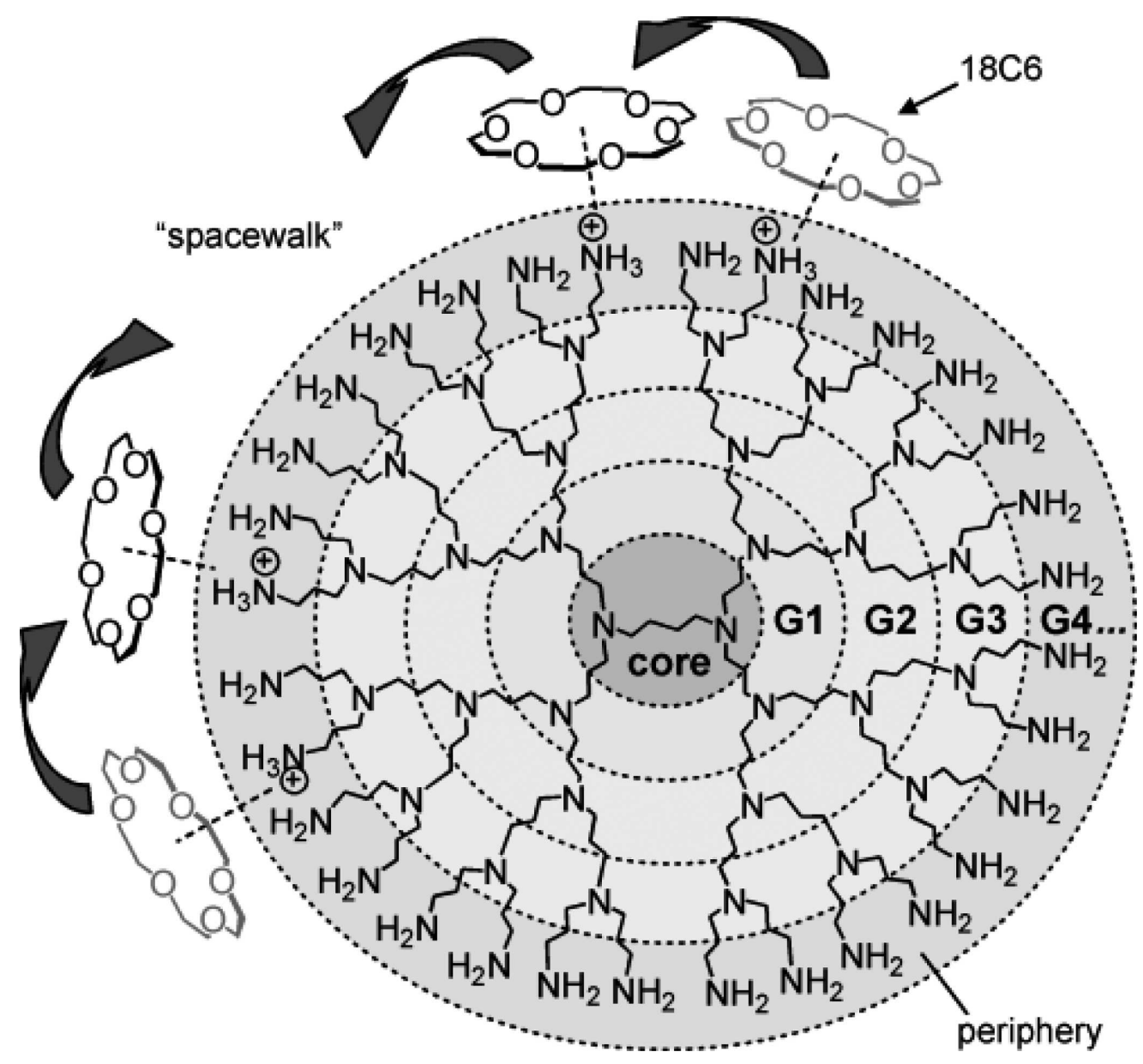

$174 \times 162 \mathrm{~mm}(600 \times 600 \mathrm{DPI})$ 

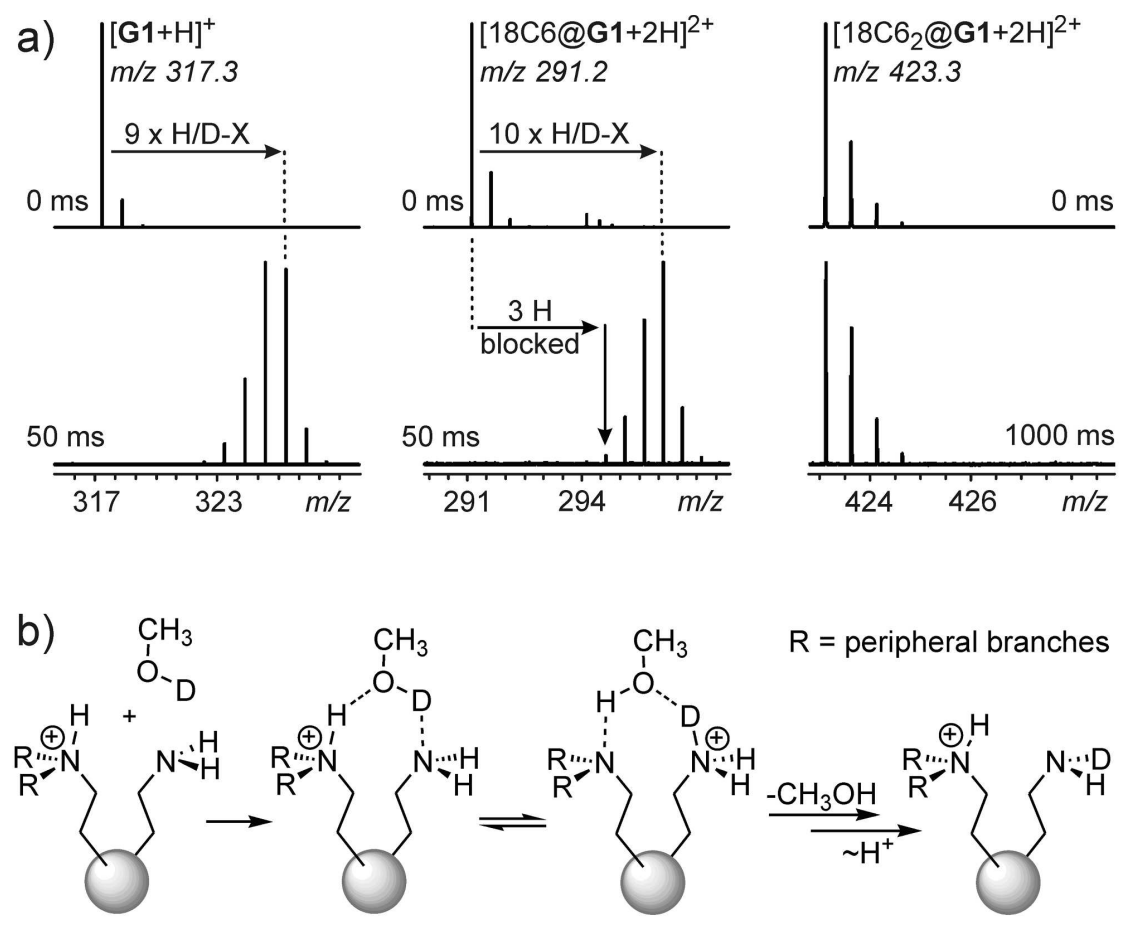

$\mathrm{R}=$ peripheral branches

C) $[18 \mathrm{C} 6 @ \mathrm{G} 2+2 \mathrm{H}]^{2+}$

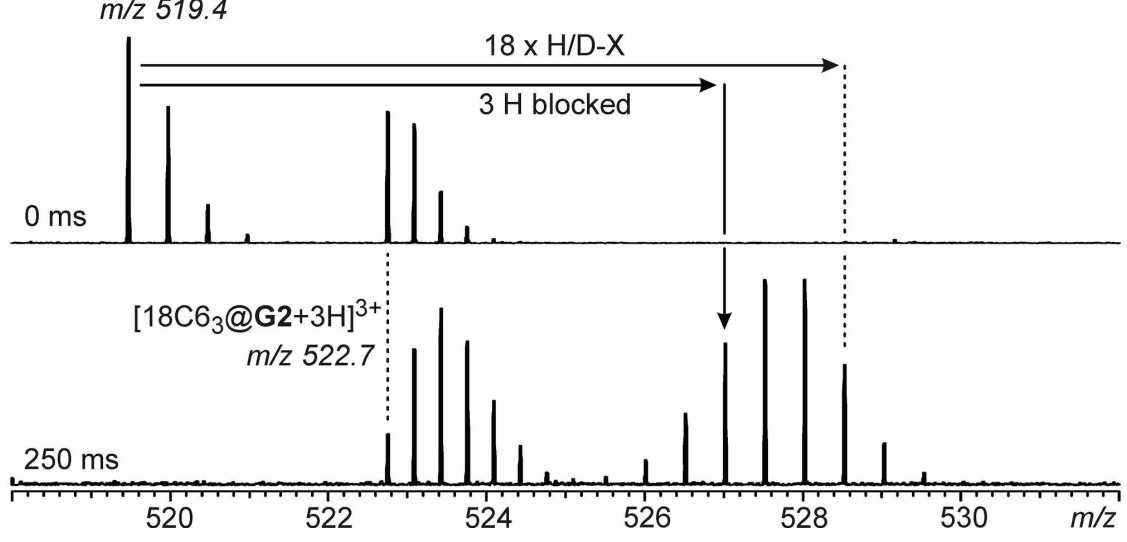

$169 \times 237 \mathrm{~mm}(600 \times 600 \mathrm{DPI})$ 

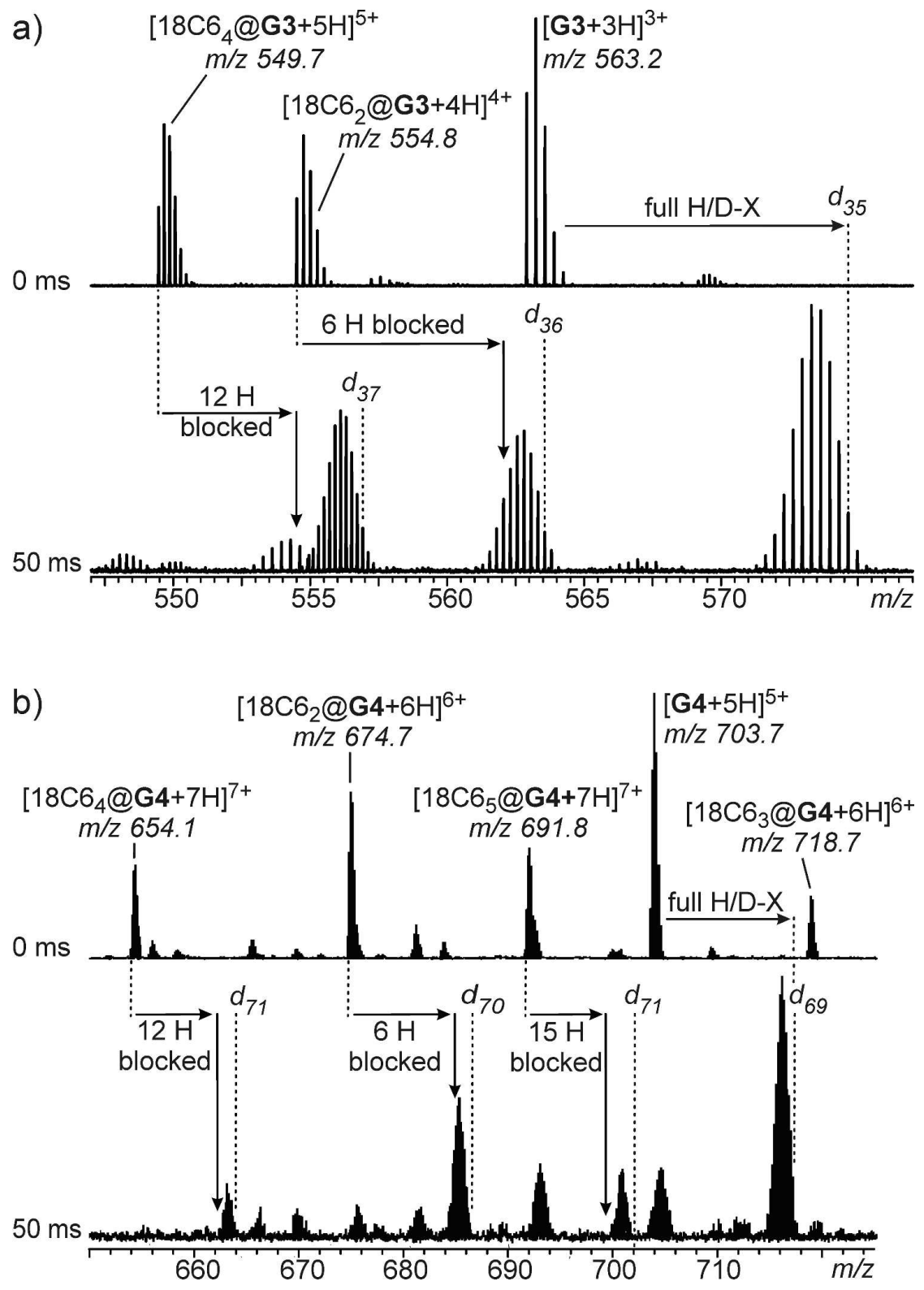

$127 \times 178 \mathrm{~mm}(600 \times 600 \mathrm{DPI})$ 

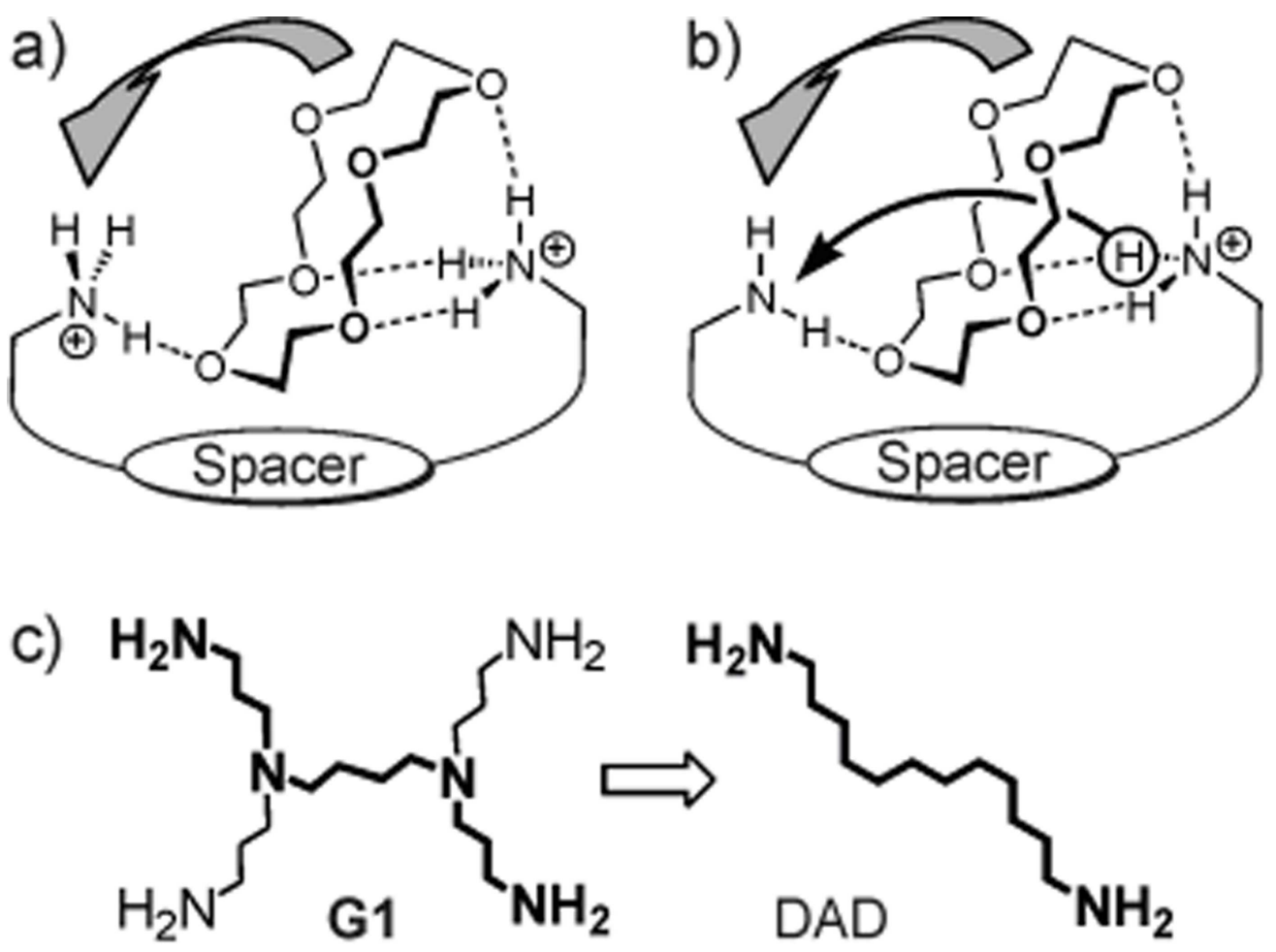

$118 \times 91 \mathrm{~mm}(600 \times 600 \mathrm{DPI})$ 
2010-03-15

zhenhuiqi

发件人：Rights DE

发送时间：2010-03-15 13:17:46

收件人：zhenhuiqi@gmail.com

抄送：

主题: AW: Form: Permission request

Dear Customer,

Thank you for your email.

We hereby grant permission for the requested use expected that due credit is given to th e original source.

- For material published before 2007 additionally: Please note that the (co-

) author's permission is also required.

If material appears within our work with credit to another source, authorisation from that source must be obtained.

Credit must include the following components:

Books: Author(s)/ Editor(s) Name(s): Title of the Book. Page(s). Publication year. Copyr ight Wiley-VCH Verlag GmbH \& Co. KGaA. Reproduced with permission.

J ournals: Author(s) Name(s): Title of the Article. Name of the Journal. Publication year. Volume. Page(s). Copyright Wiley-

VCH Verlag GmbH \& Co. KGaA. Reproduced with permission.

With kind regards

Bettina Loycke

***************************************************

Bettina Loycke

Senior Rights Manager

Wiley-VCH Verlag GmbH \& Co. KGaA

Boschstr. 12

69469 Weinheim

Germany

Phone: +49 (0) 62 01- 606 - 280

Fax: $\quad+49$ (0) $6201-606-332$

Email: rights@wiley-vch.de

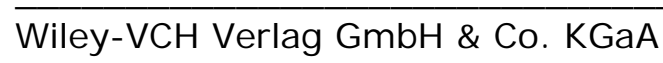

Location of the Company: Weinheim

Chairman of the Supervisory Board: Stephen Michael Smith

Trade Register: Mannheim, HRB 432833

General Partner: John Wiley \& Sons GmbH, Location: Weinheim

Trade Register Mannheim, HRB 432296

Managing Directors : Christopher J. Dicks, Bijan Ghawami, William Pesce

-----Ursprüngliche Nachricht-----

Von: zhenhuiqi@gmail.com [mailto:zhenhuiqi@gmail.com]

Gesendet: Montag, 15. März 2010 13: 15

An: Rights DE

Betreff: Form: Permission request

Form: Permission request

Path: Service Permission Request

Language: en

Adress 


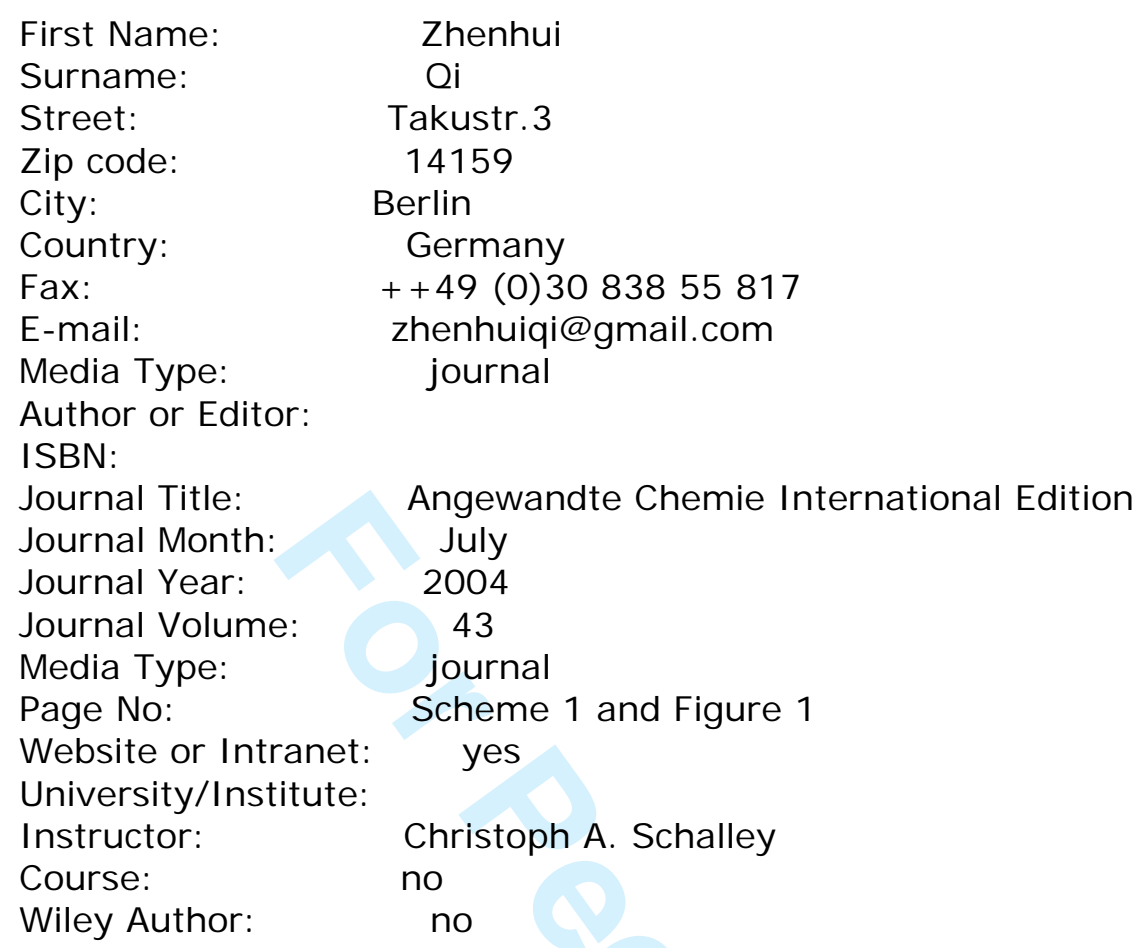


Dear Chris,

It is my great pleasure to give permission and many thanks for taking our work into account.

With best regards,

Bert

From: Prof. Dr. Christoph Schalley [mailto:christoph@schalley-lab.de]

Sent: maandag 15 maart 2010 14:59

To: Meijer, E.W.

Cc: z.qi@schalley-lab.de

Subject: Copyright permission

Dear Bert,

Supramolecular Chemistry is organizing a memorial issue for Dmitry Rudkevich. We have put together a mini-review on dendrimer host-guest chemistry in the gas phase (manuscript is attached) highlighting your nice work "multivalency in the gas phase" in Angewandte. May we use the Figure again (Figure 2 in the manuscript)? Some time ago, you already permitted me to use it in a book, but I wanted to be sure that it is ok, if we use it again.

Best wishes,

Chris

Prof. Dr. Christoph A. Schalley

Institut für Chemie und Biochemie der Freien Universität Berlin

Takustr. 3

14195 Berlin

Germany

phone: +49-(0)30 838-52639

fax: +49-(0)30 838-55817

email: christoph@schalley-lab.de

http://www.chemie.fu-berlin.de/ schalley 